\title{
Hidden benefits and risks of partial protection for coral reef fisheries
}

\author{
$\underline{\text { Patrick F. Smallhorn-West }}^{1,2}$ (D) , Philippa J. Cohen ${ }^{1,2}$ (D), $\underline{\text { Renato A. Morais }}^{1,3}, \underline{\text { Fraser A. Januchowski-Hartlev }}^{4}$ (D) , Daniela \\ Ceccarelli $^{1}$, Siola'a Malimali $^{5}$, Karen Stone $^{6}$, Regon Warren $^{2}$ and Joshua E. Cinner $^{1}{ }^{10}$
}

\begin{abstract}
Partially protected areas are now the dominant global form of spatial management aimed at preserving ecosystem integrity and managing human use. However, most evaluations of their efficacy use only a narrow set of conservation indicators that reflect a fraction of ways in which protection can succeed or fail. In this paper, we examine three case studies of partially protected coral reef fishery systems to evaluate benefits and risks of their use as a management tool. We use data from community-based management arrangements in three Pacific Island countries to demonstrate three vignettes of how partial protection can boost fisheries production, enhance the ease with which fishers catch their prey, and alter the composition of fisheries yields. These changes in fisheries productivity, catchability, and vulnerability under partial protection carry substantial benefits for fishers. However, they also carry significant risks for ecosystems and fisheries livelihoods unless adaptively managed so as to confer the short to medium term benefits in resource performance without risking longer term sustainability.
\end{abstract}

Key Words: community-based marine management; conservation; impact evaluation; local management; marine protected area; traditional ecological knowledge

\section{INTRODUCTION}

A critical need of the 21st Century is to balance the preservation of nature with its sustainable use (Halpern et al. 2013). Protected areas limiting resource extraction have become a popular tool for the management of terrestrial, marine, and inland aquatic systems (Joppa and Pfaff 2011, Edgar et al. 2014, Visconti et al. 2015). The use of protected areas continues to expand, with a suggested target of $30 \%$ of the planet to be placed under some form of spatial management by 2030 (Waldron et al. 2020). However, controls and limits within protected areas can vary in the degree to which and for whom the use of resources is restricted. Although full closures (where extractive activities, and even access, are prohibited) can confer substantial benefits for biodiversity conservation over time (Joppa and Pfaff 2011, Edgar et al. 2014), they can also carry substantial costs. These costs may be particularly high in the short term and in areas where people's livelihoods and food security are dependent on the resources within those boundaries (Ferraro and Hanauer 2011, Brockington and Schmidt-Soltau 2017). As a result, in many instances the total exclusion of people from an area and a total ban on using resources upon which they rely is neither politically nor economically feasible and may incur substantial socioeconomic costs (Halpern et al. 2013).

Although it is desirable that the full suite of tools available for management are considered, in many contexts the objectives and values of stakeholders will exclude certain tools from the solution space (McClanahan et al. 2012, Haasnoot et al. 2020). Partially protected areas (PPAs), which allow limited extraction of resources from within boundaries, are a widely applied measure that regulates when, how, and by whom harvesting occurs (Jupiter et al. 2014, Zupan et al. 2018, Turnbull et al. 2021). Partially protected areas now constitute the dominant form of marine spatial management globally ( $69 \%$ of all marine managed areas) (Turnbull et al. 2021). However, as a management tool, the value of PPAs differs depending on whether the desired outcomes are rooted in conservation or food security and livelihoods, and there is mixed evidence of ecological benefits from PPAs (Lester and Halpern 2008, Giakoumi et al. 2017, Sala and Giakoumi 2018, Zupan et al. 2018, Turnbull et al. 2021). For example, in fisheries, partial protection has been shown to simultaneously improve fish biomass, parrotfish grazing, and trait diversity, but only in certain socioeconomic contexts, and to a much lesser extent than full protection (Cinner et al. 2020). Partial protection can confer significant livelihood benefits, such as improvements in harvest efficiency within closures when they are periodically opened to harvesting (Cohen and Alexander 2013, Goetze, et al. 2017, Carvalho et al. 2019, Cinner et al. 2019). Yet, increased harvest efficiency can also lead to overharvesting if not managed properly (Robinson et al. 2015, Goetze et al. 2017).

Differences in governance structures under which PPAs are implemented might also lead to different outcomes. For example, benefits may be more likely when partial protection rules are collectively developed in bottom-up or collaboratively managed (often referred to as co-managed) systems, which tend to receive high levels of legitimacy and compliance, compared with when the same rules are dictated by top-down systems (Ban et al. 2019).

Here, we use the lens of co-managed coral reef systems to illustrate the fisheries benefits and risks of partial protection under these regimes. We assess how three fisheries indicators - potential fisheries productivity, individual fish catchability, and intrinsic vulnerability - in PPAs compare with openly fished areas and/or those under full protection across three case studies from Pacific island nations. We examine: (1) potential fisheries productivity in Tonga; (2) individual fish catchability in Vanuatu; and (3) intrinsic vulnerability to catch in Solomon Islands (Fig. 1; Table 1). We note that examining these three cases does not reflect a fully crossed sample design; the data in each case were suited to assess

\footnotetext{
${ }^{1}$ Australian Research Council Centre of Excellence for Coral Reef Studies, James Cook University, Townsville, Queensland 4811 Australia, ${ }^{2}$ WorldFish, Jalan Batu Maung, Bayan Lepas, Penang, Malaysia, ${ }^{3}$ Research Hub for Coral Reef Ecosystem Functions, College of Science and Engineering, James Cook University, Australia, ${ }^{4}$ Department of Biosciences, Faculty of Science \& Engineering, Swansea University, Swansea, UK, ${ }^{5}$ Tonga Ministry of Fisheries, Sopu, Nuku'alofa, Tonga, ${ }^{6}$ Vava'u Environmental Protection Association (VEPA), Vava'u, Tonga
} 
Fig. 1. Map of the South Pacific with the three indicators and cases included in this study. Productivity represents the rate of production of new biomass based on the growth rate of individual species (Morais and Bellwood 2020). Catchability represents the probability of approach to within spearing distance (mean $3.37 \mathrm{~m}$, range $3.05-3.60 \mathrm{~m}$ ) of a reef fish, thus representing the trade-off between catch and effort (Januchowski-Hartley et al. 2014). Vulnerability represents how susceptible fish species are to overfishing (scaled 0-100) based on key life-history characteristics (Cheung et al. 2007). Each management strategy represents one approach that can be employed under co-management arrangements, although these are not mutually exclusive. Partially protected areas (green) limit when, how, or by whom harvesting occurs. No-take reserves (red) are those in which all fishing is permanently banned. The exact location of the study community in Solomon Islands is not shared due to confidentiality agreements between the community and the partner organization, WorldFish.

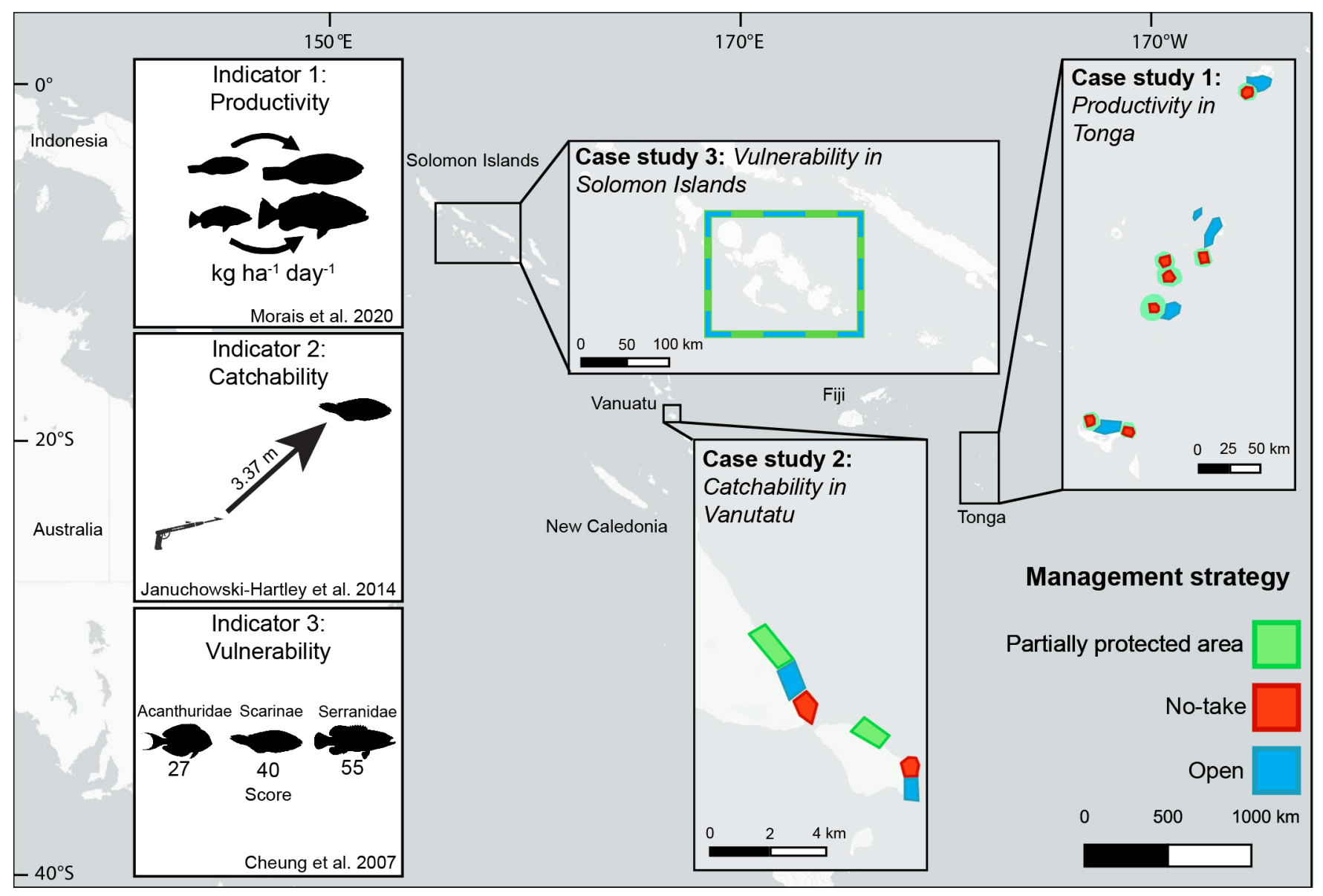

only one of the available indicators. However, the findings from each case represent ways in which PPAs can affect fisheries performance and are hence useful to explore in conjunction, despite limitations on extrapolating these findings across other systems (as also occurs in most studies of individual cases). We also note that many marine management areas explicitly target conservation outcomes and the maintenance of ecological function, whereas our synthesis focuses on fisheries outcomes. Yet, together, these case studies - two of which discuss findings across a network of management areas (productivity and catchability in Tonga and Vanuatu, respectively) and one of which across a decade of monitoring (vulnerability in Solomon Islands) - provide a collection of vignettes that illustrate key benefits and risks partial protection can carry for sustainable resource management.

\section{SYNTHESIS}

\section{Productivity}

Potential fisheries productivity (hereafter "productivity") $\left(\mathrm{kg} \mathrm{ha}^{-1}\right.$ day $^{-1}$ ) represents the rate of biomass accumulation of target fish in a system based on the expected growth and survival of observed individuals according to their species and size (Morais et al. 2020). This provides a more direct link to fisheries yields and biomass build-up (MacNeil et al. 2015) than standing biomass, as biomass is a static measure resulting from production accumulated over an unknown timeframe. Productivity therefore represents an independent indicator of potential fisheries yield (i.e., what can be harvested) from target fish assemblages in high-diversity tropical ecosystems. Productivity is calculated as the balance of two opposed dynamics acting over individual fishes: somatic growth and mortality. The first component, daily growth, is 
Table 1. Details of case studies from three South Pacific countries that examine the influence of co-management on fisheries indicators. UVS = Underwater visual survey; PPA = partially protected area.

\begin{tabular}{|c|c|c|c|c|c|c|c|}
\hline $\begin{array}{l}\text { Case } \\
\text { study }\end{array}$ & Country & Indicator & $\begin{array}{c}\# \\
\text { Communities }\end{array}$ & Time period & Data type & Sample size & Characteristics of PPA \\
\hline 1. & Tonga & Productivity & 7 & $2016-2018$ & UVS transects & 1635 transects & Fishing access and use limited to community members \\
\hline 2. & Vanuatu & Catchability & 2 & 2011 & $\begin{array}{c}\text { Behavioral } \\
\text { surveys }\end{array}$ & 288 fish & $\begin{array}{l}\text { Fishing access and use limited to community members } \\
\text { during predetermined opening events of } 3-7 \text { days } \\
\text { every } 6 \text { months }\end{array}$ \\
\hline 3. & $\begin{array}{l}\text { Solomon } \\
\text { Islands }\end{array}$ & Vulnerability & 1 & 2010-2019 & Catch surveys & 993 trips & $\begin{array}{l}\text { Fishing access and use limited to community members } \\
\text { during predetermined opening events of } 2-4 \text { weeks } \\
\text { each year. }\end{array}$ \\
\hline
\end{tabular}

quantified from von Bertalanffy Growth Model trajectories predicted from morphological and behavioral traits (maximum species body size, diet, position relative to the reef, and sea surface temperature). The second component, mortality, is then incorporated via a probabilistic routine that assigns fate (survival vs. mortality) to individual fishes using their expected instantaneous mortality rates estimated from species, individual body size, and sea surface temperature (Morais et al. 2019). For detailed methodology on the calculation of potential fisheries productivity refer to Morais and Bellwood (2020).

Although calculating fisheries production is not a new concept (e.g., Brock 1985, Welcomme and Bartley 1998, Finney et al. 2002), a readily quantified metric of productivity for multi-species coral reef systems has only recently become available. Morais and Bellwood (2020) provide a detailed framework and R package (rfishprod) for quantifying potential fisheries productivity in highdiversity coral reefs using the same underwater visual survey data that are frequently used to quantify standing fish biomass. Thus far, research has revealed that the relationship between standing fish biomass and potential fisheries productivity is not tightly coupled, and therefore, the assumption that biomass accurately represents potential fisheries yields may not hold (Morais et al. 2020). Standing fish biomass and potential fisheries productivity respond differently to rates of exploitation: as size-selective exploitation depletes fish biomass, it triggers increased production per unit of biomass, which in both modeled and empirical systems has avoided immediate productivity collapse. This process, termed "buffering productivity," demonstrates the danger of using biomass estimates as a proxy for fisheries potential and also may help explain why some reefs with depleted standing biomass can nevertheless support active fisheries (Jennings and Polunin 1996, Morais and Bellwood 2020). Globally, there are also substantial differences in productivity estimates between reef fish functional groups, with most productivity in reef fish assemblages originating from planktivorous species and water column photosynthesis, rather than enclosed reef energetic pathways (Morais et al. 2019, 2021). Importantly, these high rates of planktivorous productivity can also be maintained on impacted reefs with low coral cover, offering hope that reef systems subjected to coral loss can still maintain high fish productivity and hence sustain active fisheries if managed appropriately.

\section{Catchability}

A key rationale for implementing periodically harvested PPAs is to change fish behavior so that they are more easily approachable, and thus easier to catch (Foale et al. 2011). Individual fish catchability (hereafter "catchability") is defined as the ease with which a fisher can catch a fish independent of stock density and is calculated based on the probability of a fisher approaching to within spearing distance of a target reef fish. Spearing distance can be determined from fisher interviews where fishers are asked to estimate the maximum effective range of their spearguns, or how close to a fish they would have to be for a spearing attempt to be successful (Januchowski-Hartley et al. 2014). Fisher approach distance is then calculated based on behavioral surveys (approaching a fish underwater with a spear in hand) of fish wariness using flight initiation distance (FID). Spearing distance can vary based on fisher experience and gear quality, as well as context-specific factors such as sea condition. A high (or long) FID combined with a short spearing distance suggests a fish has a low catchability, whereas a low (or short) FID combined with a high spearing distance suggests a fish has a high catchability.

Although the relationship between management and fish wariness has been well documented (e.g., Januchowski-Hartley et al. 2012, 2013, 2014, 2015, Goetze et al. 2017), the degree to which this affects the actual probability of capture by fishers has not yet been quantified, nor how this is influenced by size selectivity. Changes in fish wariness have been shown to be strongly influenced by marine management, with FID typically decreasing rapidly with management implementation, sooner than do other impacts such as biomass accumulation, and then quickly increasing again following significant harvesting events (Januchowski-Hartley et al. 2014). This dynamic response is likely a key reason why indigenous peoples and local communities have been managing their waters using periodically harvested PPAs for centuries (Cohen and Steenbergen 2015). These changes also occur at broad spatial scales and along a gradient of exploitation, with increasing levels of net fishing pressure driving increased fish wariness not only beyond, but also within no-take reserves (JanuchowskiHartley et al. 2015). Fish naïveté can also spill over from managed areas to surrounding fished areas and persist at a greater distance than changes in other variables such as standing biomass (Januchowski-Hartley et al. 2013). In addition, both target (Sbragaglia et al. 2018) and non-target (Tran et al. 2016) species can also readily distinguish spearguns, demonstrating that fish can develop fine antipredator responses and recognize the risks posed by spearfishers as predators.

\section{Vulnerability}

Intrinsic vulnerability to fishing is defined as the inherent capacity of a species to withstand the additional mortality imposed by 
exploitation, determined primarily by the intrinsic rate of population growth ( $r$ ) (Abesamis et al. 2014). Importantly, intrinsic vulnerability differs from extrinsic vulnerability, which is based on patterns of exposure to risks. For example, throughout this manuscript the use of PPAs, no-take closures, and openly fished areas represent differences in levels of extrinsic vulnerability, whereas differences in key life-history characteristics of species represent their intrinsic vulnerability (hereafter "vulnerability") to over-exploitation from fishing. Using a fuzzy logic expert system, Cheung et al. (2007) developed a vulnerability index for 1353 fish species and 87 families (scaled 1-100, with 100 being the most vulnerable to over-exploitation) based on eight life-history and ecological characteristics (maximum length, age at first maturity, longevity, growth rates, natural mortality, fecundity, spatial behavior, and geographic range). Abesamis et al. (2014) then added a further 145 targeted species of coral reef fishes belonging to ten families using the same methodology. The input variables consisted of traits that were considered to be related to the species intrinsic vulnerability and were obtained from a literature review (Cheung et al. 2005). Briefly, the expert system classified fish species into different life-history categories with different degrees of association, ranging from 0 (no association) to 1 (full association) and was determined by predefined fuzzy logic membership functions (Cheung et al. 2005). Linguistic rules expressed as IF (predicate) - THEN (conclusion) clauses were used to infer the levels of species vulnerability (e.g., IF maximum length is large THEN intrinsic vulnerability is high). This composite metric provides a simple way of characterizing the overall risk of exploitation for multi-species fisheries, with declines in mean values indicating fewer vulnerable species (e.g., those with slow growth and low fecundity) present in the catch.

Since 1950, global fish catch has been increasingly dominated by species with low intrinsic vulnerability (Cheung et al. 2007). This pattern is most pronounced on coral reefs, where catches in 2005 comprised species $25 \%$ less vulnerable than in 1950 . Vulnerability is also significantly correlated with observed rates of population declines from a wide range of data sets and ecosystems, with overfishing consistently driving declines in overall vulnerability scores as the more vulnerable species (i.e., those with a higher score) are overfished and no longer present in the system (Cheung et al. 2005). These trends have also been used on coral reefs to predict patterns of species recovery, with highly vulnerable species taking significantly longer time (i.e., decades) to attain local carrying capacity than less vulnerable species (Abesamis et al. 2014).

\section{MATERIALS AND METHODS}

\section{Case Study 1: Productivity in Tonga}

In 2002, Tonga established the Special Management Area (SMA) program, which is a collaborative fisheries management approach between Tongan communities and the Ministry of Fisheries (Smallhorn-West et al. 2020a). It represents a two-part approach to marine management, in which communities are granted exclusive access to the area of reef surrounding their community (i.e., the PPA) in exchange for making part of it a no-take reserve. The first Special Management Area was implemented in 2006, and the program currently includes $>100$ no-take or restricted access PPAs across $>50$ communities. Our research examined the impact of the SMA program on patterns of reef fish productivity and biomass (Fig. 1). Specifically, we build on previous studies that have explored standing stock biomass, density, and size, as well as overall species diversity (Smallhorn-West et al. 2020b), by calculating the rate at which biomass of target fishes is produced (i.e., potential fisheries productivity) in openly fished, restricted access PPAs, and fully closed areas. Our impact evaluation covers only management areas established prior to 2014 and at least 3 years old at the time of ecological surveys. In this study, therefore, we included seven communities that each implemented one notake reserve and one restricted access PPA in which only members of that community can fish. The size of the no-take reserves and PPAs ranges from $0.5-2 \mathrm{~km}^{2}$ and $5-40 \mathrm{~km}^{2}$, respectively.

Ecological surveys were conducted from 2016 to 2018 across 375 sites in Tonga, both within management areas (seven no-take and seven restricted access) and at potential control sites. At each site, four to six $30-\mathrm{m}$ belt transects (total 1635) were laid parallel to the reef contour at depths of 3-12 $\mathrm{m}$ (the depth at which fishing is most common), with a minimum of 12 transects within each community's no-take and restricted access areas. All transects were conducted between 9 a.m. and 4 p.m. The abundance and size of all large mobile fish were recorded to species level within a 5-m belt, and all small, site-attached reef fish species were recorded along a 2-m belt. The length and abundance of all reef fish were converted to transect level productivity using the rfishprod package (Morais and Bellwood 2020), which provides productivity estimates for individual reef fish species, and to biomass following published length-weight relationships (https:// www.fishbase.com). Species were also classified as target or nontarget based on 226 household interviews from seven SMA communities, which discussed patterns of fishing and fish consumption (Parks 2017).

Statistical matching was then used to compare productivity and biomass estimates within no-take reserves and PPAs to predicted counterfactual conditions, which represent estimates of those same areas under the absence of management (Olmos and Govindasamy 2015, Ho et al. 2018). We selected nine contextual factors to use for matching that encompassed environmental and social features of coral reefs that are known to influence either the response variable or the configuration of protected areas (Append. 1, Table A1). Details of these variables are available in Smallhorn-West et al. (2019). These factors included: fishing pressure, wave energy, depth, slope, habitat complexity, coral cover, habitat, island group, and surveyor. No-take and PPA transects were matched to the same overall pool of control transects. The variables habitat type, island group, and surveyor were all fixed so that control transects could be paired only with managed transects if they matched the exact combination of these covariates. Following fixed matching, all remaining covariates were weighted equally, and we assessed covariate balance (i.e., the difference between distributions of covariates across treated and control transects) achieved by multiple matching algorithms, including propensity score and Mahalanobis matching (Olmos and Govindasamy 2015). The Mahalanobis distance metric produced the smallest mean differences between managed and control transects, with no evidence of imbalance for either notake reserves or PPAs (Append. 1, Table A1). A pre-specified tolerance (i.e., caliper) of 0.25 standard deviations of the sample estimated propensity scores was set to ensure only high quality matches (Rosenbaum and Rubin 1983). All statistical matching 
procedures were performed in R 4.0.2 (R Core Team 2016) using the MatchIt package, and a total of 324 no-take reserve or PPA transects were matched, with only three remaining unmatched (Append. 1, Table A2).

Finally, linear mixed effects models using the glmer function, with community and site included as random factors, and site nested within community, were used to test overall differences in both target and total productivity and biomass between no-take reserves or PPAs and matched open transects. Models were fit with both fixed and random slopes using a gamma log link distribution and the one with the lowest Akaike Information Criterion (AIC) score included. Model fit was examined using partial residual plots and tested with chi-squared tests on the residual sum of squares and residual degrees of freedom.

\section{Case Study 2: Catchability in Vanuatu}

In Vanuatu, we used behavioral surveys of fish to quantify how the probability of capture from spearfishing differs between openly fished areas, PPAs, and fully closed areas. We build upon previous studies of fish behavior, which measured the distance at which fish flee (flight initiation distance) (Januchowski-Hartley et al. 2014), by integrating average fisher spearing distance to estimate probability of capture in each zone and to calculate how catchability varies by size. Flight initiation distance (FID) surveys were conducted adjacent to two communities in the Nguna-Pele Marine Protected Area Network in Vanuatu in December 2011 (Fig. 1). The Nguna-Pele Marine Protected Area Network is a collaborative management initiative started in 2002 that encompasses 16 villages, government ministries, nongovernmental organizations, international volunteer organizations, and research institutes. Each community reef area consisted of a periodically harvested PPA, where fishing was only allowed by community members for 3-7 days every 6 months, a no-take zone that had been in place for 6 years, and reef area open to fishing (Januchowski-Hartley et al. 2014). All no-take reserves and PPAs enclosed between .08 and $.1 \mathrm{~km}^{2}$ of fringing reef, and openly fished areas enclosed between .14 and $.16 \mathrm{~km}^{2}$ of reef. We acknowledge that spearfishing is only one method employed in the harvesting of reef fish, but additional analysis of other methods such as line or net fishing were beyond the scope of this study. Although this sampling design was unable to statistically control for co-variates such as habitat, wave energy, or distance from village, a coarse matching approach was employed whereby the openly fished areas were compared when they were thought to be the most similar to those reefs under management, based on expert opinion (Ahmadia et al. 2015).

In each area, FID was measured for 24 individual fishes from each of the two most commonly caught reef fish groups: Acanthuridae (surgeonfish and unicornfish) and Scarinae (parrotfish), all with a minimum total length of $15 \mathrm{~cm}$ (Acanthuridae) and $20 \mathrm{~cm}$ (Scarinae). Only species that occurred in the fishery catch were sampled for each target family, and similar species were sampled from each area. Estimates of FID were obtained through freediving, where the observer (FAJ) identified a focal fish from the surface, before descending to approximately the same depth at $>8$ $m$ distance (Januchowski-Hartley et al. 2014). The observer then swam toward the fish at a steady speed until the fish fled. At this point, the observer placed a marker on the substrate directly below his face, and a second at the point where the fish began to flee, and the distance between these two points is considered to be the FID. The size (cm TL) of each individual was visually estimated prior to the approach.

Kreel surveys suggest that the dominant gear for reef fishing was spearguns, used on 33 out of 43 fishing trips (six night-spearing), with nets the second most common gear used on nine fishing trips. Fisher interviews suggested that hook and line were also commonly used as a secondary gear during speargun trips. During the interviews, each fisher $(n=14)$ was asked to estimate the maximum effective range of spearguns (measured from the fisher's face). The mean maximum effective range was estimated at $337 \mathrm{~cm}$, with a range of $305-360 \mathrm{~cm}$. Due to most fishers not attaching their spear to their spearguns, and thus the risk of losing the spears if a shot is unsuccessful, the probability of a successful spearing attempt at this distance is likely high.

Individual fish were categorized into "captured" or "escaped" based on whether FID was greater or smaller than speargun range for the mean, lowest, and highest estimated ranges (Append. 1, Table A3). Binomial logistic regression models with $\mathrm{z}-$ standardized total length and management type were first conducted for all Acanthuridae and Scarinae to identify differences in catchability between management types, followed by each combination of fish group and management type to model the relationship between fish size and probability of capture. All analyses were conducted using the $g l m$ function in R 4.0.2 (R Core Team 2016).

\section{Case Study 3: Vulnerability in Solomon Islands}

We used the composite vulnerability metric described above (Cheung et al. 2007, Abesamis et al. 2014) to examine changes in reef-fishery catches associated with 10 years of co-management in a coastal community in Western Province, Solomon Islands (Fig. 1). Community name and location are not provided due to confidentiality agreements between them and the partner NGO WorldFish. In 2008, this community implemented two periodically harvested PPAs $\left(3.6 \mathrm{~km}^{2}\right.$ and $1.4 \mathrm{~km}^{2}$, respectively) over reef areas in their traditional fishing grounds within a broader co-management framework as part of NGO-supported initiatives to develop resource-use regulations and education, compliance, and monitoring strategies (Cohen et al. 2013). In previous studies, these PPAs are referred to as taboos or periodically harvested closures (Cohen and Alexander 2013, Cohen and Foale 2013). Since establishment, both PPAs have been managed as no access or use for much of the year (January to November) and periodically subjected to 2-week to 1-month harvesting events every December in which fishing occurs both within the PPA reefs and continues on adjacent reefs (Cohen et al. 2013). At intermittent intervals, the areas were also occasionally opened for single-night harvesting of fish for special events and feasts. Note that additional restrictions were often also in place during opening events such as the banning of net fishing or nighttime fishing within the PPAs. The total area of the PPAs was $0.86 \mathrm{~km}^{2}$, which represents approximately $15 \%$ of the total reef fishing area for this community. Previous evaluation of these specific (Cohen and Alexander 2013, Cohen and Foale 2013) and other similar (Cinner et al. 2006, Goetze et al. 2016, JanuchowskiHartley et al. 2014, Carvalho et al. 2019) PPAs have focused on single harvesting events (Cohen and Alexander 2013, Cohen et al. 2013, Goetze et al. 2017). Here, we build on these snapshot 
studies by analyzing changes in catch composition and vulnerability using catch data that span a 10 -year period over the entire fishing ground of this community.

Fishing trip and catch data were collected in five sampling periods over the course of 10 years from 2010-2020, following the methods of Cohen and Alexander (2013) and Cohen et al. (2013). Each sampling period lasted approximately 1 month and corresponded with the main timing of PPA opening, so that data were collected for a minimum of 1 week on either side of opening events. During sampling periods, the details were recorded of all fishing trips conducted to both partially protected areas (when opened, $n=813$ ) and those open to fishing year round, $n=1369$ fishing trips (total days sampling $=138$ ). Due to funding and fieldwork realities, we were unable to sample every year, and the sampling intervals were uneven. In each sampling period, at least one observer was posted at village landing sites day and night, and as soon as fishers returned to shore, they were asked to recount the details of the trip, including fishing location and management zone. The number and species of each catch was then recorded using local language names, which were subsequently converted to the highest taxonomic resolution possible following Cohen et al. (2014). Each fish was then assigned a vulnerability score available in the supplementary materials of either Abesamis et al. (2014) or Cheung et al. (2007), based on which provided the highest taxonomic resolution. An additional analysis was completed with only family-level scores, and the results did not differ substantially.

Generalized additive models were used to examine changes in the mean vulnerability of catch from fishing trips through time between open and partially protected reefs, with management and time included as fixed effects. Up to four knots were allowed to be fit within the spline, but with less if it resulted in a better model fit. Models were fit using Gaussian distributions, and final model selection was based on the lowest AIC score. Model fit was assessed by examining residual histograms and fitted values vs. residuals, which in both cases suggested model fit was acceptable. All analysis was completed in R 4.0.2 (R CoreTeam 2016) using the gam and visreg functions.

\section{RESULTS AND DISCUSSION}

\section{Case Study 1: Productivity in Tonga}

Our surveys in Tonga reveal that both the no-take reserves and PPAs have significantly higher potential fisheries productivity compared with control areas (Fig. 2a,b; Append. 1, Table A4). Target reef fish productivity was approximately $60 \%$ greater inside PPAs ( $\left.1.06 \mathrm{~kg} \mathrm{ha}^{-1} \mathrm{day}^{-1} \pm 0.17 \mathrm{SE}\right)$ where fishing is still allowed by community members, and in no-take reserves $\left(1.20 \mathrm{~kg} \mathrm{ha}^{-1}\right.$ day $\left.^{-1} \pm 0.018 \mathrm{SE}\right)$, compared with statistically matched control sites open to fishing $\left(0.64 \mathrm{~kg} \mathrm{ha}^{-1} \mathrm{day}^{-1} \pm 0.11 \mathrm{SE}\right.$, and $0.76 \mathrm{~kg} \mathrm{ha}^{-1}$ day $^{-1} \pm 0.076 \mathrm{SE}$, respectively). In contrast, significant differences in standing biomass of target species were only observed for notake reserves, when compared with openly fished areas and PPAs (Fig. 2c,d).

Biomass gains within areas closed to fishing are frequently reported (MacNeil et al. 2015, Cinner et al. 2018, Smallhorn-West et al. 2020b), but these gains are inconsequential for fisheries unless spillover occurs of adult fish or larvae subsidies into fishing grounds, for which evidence is less common (but see Halpern et al. 2009, Harrison et al. 2012). In contrast, greater productivity in these PPAs, where some fishing still occurs, should lead to improved catches for fishers, even if standing biomass remains lower than can be achieved with a full ban on fishing. The difference in target species productivity between the PPAs included in this study and open-access areas is $0.42 \mathrm{~kg} \mathrm{ha}^{-1} \mathrm{day}^{-1}$, or a $65 \%$ increase in productivity, which may indicate the potential increase in rates of extraction, from partial protection. Of course, if the PPA reef fish community recovery continues, the size structure of the fish community will also change toward larger fish, which contribute less to potential daily growth (Morais and Bellwood 2020). However, given that Tonga's network of community-enforced access restrictions now covers a total reef area of $96.9 \mathrm{~km}^{2}$ (Smallhorn-West et al. 2020a), it is reasonable to expect approximately 4.1 tons of daily fish production in excess of what would be produced if this reef area was open to fishing to be available across the country as a result of co-management.

Fig. 2. Impact of no-take reserves and PPAs on target $(a, c)$ and total $(b, d)$ productivity and biomass from Tonga's Special Management Area program. Red and green circles represent mean values within management areas. Blue circles represent mean estimated counterfactual values in areas open to fishing, with transects statistically matched according to nine socioenvironmental variables (Append. 1, Tables A1, A2). Error bars denote $95 \%$ confidence intervals. Asterisks indicate significant differences $(\mathrm{p}<0.05)$ in values between managed areas and predicted counterfactual conditions.
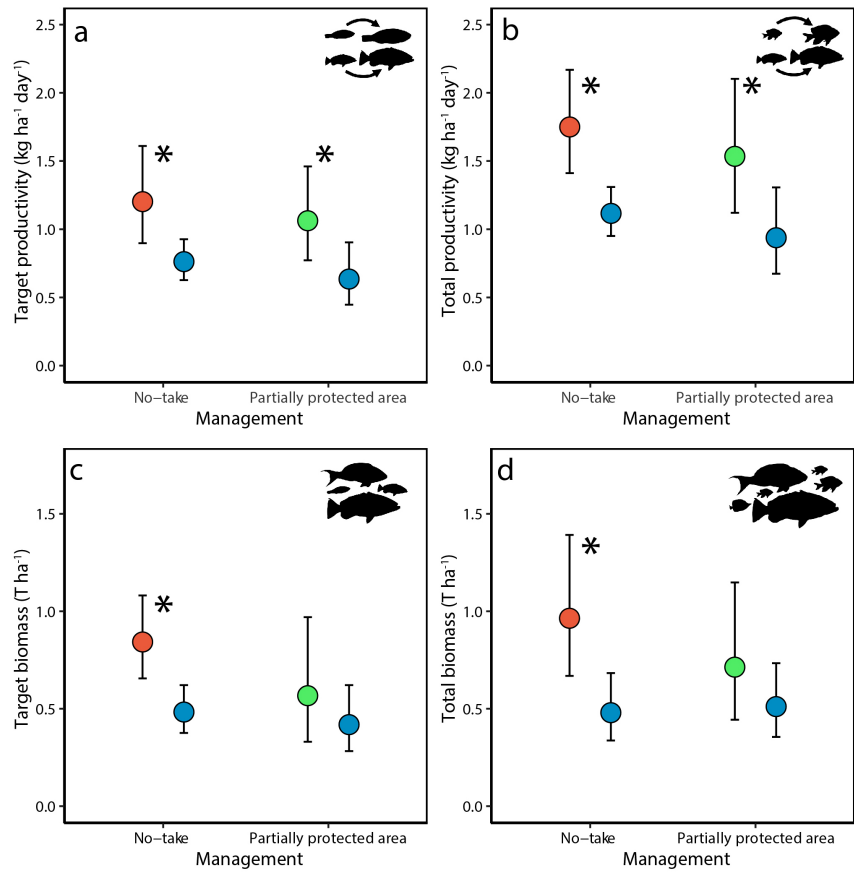

Case Study 2: Catchability in Vanuatu

Our surveys revealed size dependency in the catchability of Acanthuridae and Scarinae between management strategies (Fig. 3; Append. 1, Table A5). As fishing restrictions increased (from openly fished reefs to PPA to no-take reserves), so too did the 
Fig. 3. Differences in probability of approaching within spearing range with fish size (total length) for the family Acanthuridae and labrid subfamily Scarinae between co-management strategies (Append. 1, Table A5). Probability of capture is defined as the likelihood of approaching to within spearing distance $(3.37 \mathrm{~m})$ of a reef fish. Gray circles are probability of capture at mean size of each fish family (Acanthuridae $22 \mathrm{~cm} \mathrm{TL}$, Scarinae $26 \mathrm{~cm} \mathrm{TL}$ ). ${ }^{*}$ by the area type indicates a significant effect of size on probability to capture at $\mathrm{p}<0.1$ and $* *$ at $\mathrm{p}<0.05$.
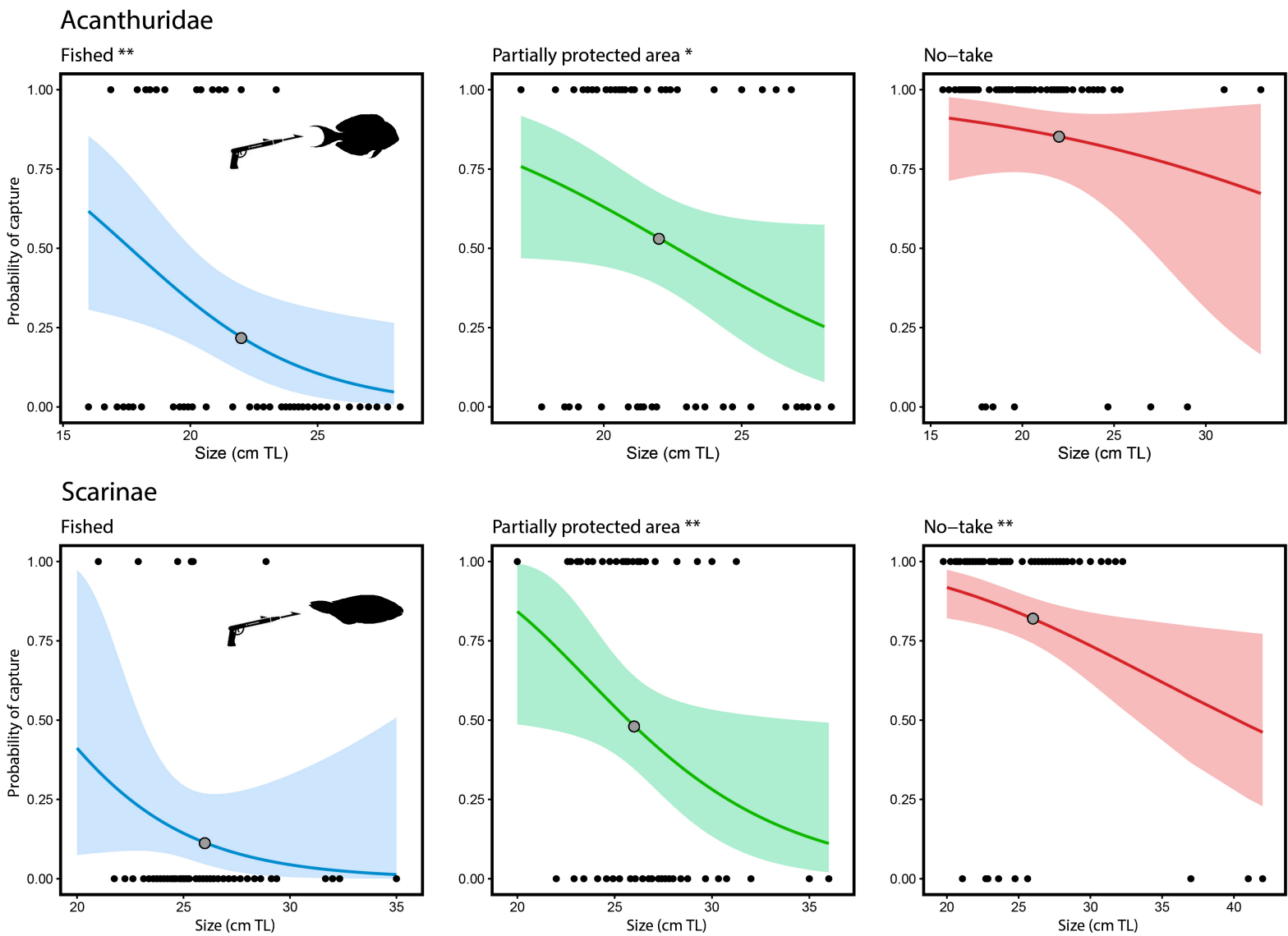

probability of approaching to within spearing range of individuals (Append. 1, Table A5). For example, for a 22-cm (TL) surgeonfish (the mean size of Acanthuridae in this study), the probability of approaching to within capture range was 0.22 $(0.12-0.39)$ on open reefs, $0.56(0.40-0.70)$ in a PPA, and 0.85 $(0.72-0.9395 \%$ CI) in a no-take zone (Fig. 3). Likewise, for the mean size of parrotfish $(26 \mathrm{~cm} \mathrm{TL})$, on open reefs, it is predicted that 1 in 10 (probability of success 0.11 , range $0.04-0.26$ ) approaches would be successful, whereas in PPAs the rate was 1 in $2(0.48$, range $0.34-0.63)$, whereas for no-take reserves 8 in 10 approaches $(0.82$, range $0.74-0.89)$ would be successful. Considering the upper and lower range of spearing distances (respectively 3.6 and $3.05 \mathrm{~m}$ ) did not affect overall trends (Append. 1, Figs. A1, A2).

Differences in catchability were also a product of fish size, with larger fish being generally more difficult to approach. However, this pattern changed with increasing fishing restrictions, so that medium-sized fish in PPAs and no-take reserves were often less wary than the smallest fish sampled in areas open to fishing. Conversely, smaller individuals were generally less wary across all forms of management. On openly fished and partially protected reefs, larger, and presumably older, fish are more likely to be wary and difficult to approach due to selective pressures from fishing, with approachable fish likely to be killed before reaching full maturity. Differences in catchability with size between management zones is likely driven by changes in individual fish behavior, rather than fisheries-driven selection, because increased wariness is evident after short-term fishing events that remove only a small fraction of the standing population, and naïveté returns following closure durations shorter than the life cycle of individuals (Januchowski-Hartley et al. 2014).

Changes in catchability under various forms of co-management have differing short- and long-term implications within the fishery. Importantly, the closing time for these periodically harvested PPAs of 6 months is far shorter than the time required for acanthurid or scarid populations to recover (Abesamis et al. 2014, Januchowski-Hartley et al. 2014). Therefore, while in the short term, improvements in catchability on these reefs due to fish naïveté is likely to bring about substantial benefits to fishers, this may come at the detriment of long-term fisheries sustainability, as well as the overall status of the ecosystem depending on the total amount harvested. This behavioral change may generate a 
form of hyperstability, where high yields mask depleted abundance, creating a false impression that the fishery is in better condition than it really is (Erisman et al. 2011, Hamilton et al. 2016, Maggs et al. 2016). Conversely, changes in catchability could also induce hyperdepletion in openly fished areas, so that low yields driven by fearful fish suggest a lower stock status than is actually present (Lennox et al. 2017). Thus, the frequency and duration of PPA openings need further consideration in order to properly manage these trade-offs (Goetze et al. 2016, 2017, 2018, Carvalho et al. 2019). Typically, PPA openings are a response to community need or desire, but aligning them with the life-history characteristics of target species would be more likely to improve the sustainability of their use (Cohen and Foale 2013).

\section{Case study 3: Vulnerability in Solomon Islands}

Analysis of the five most commonly caught fish families reveals substantial changes in composition of catches harvested from the PPAs (Fig. 4a). Over the 10-year study period, the proportion of the most commonly caught fish family, Acanthuridae $(31 \%$ of total catch across the 10-year period), declined from 54\% to $3 \%$ on periodically harvested reefs. Concurrently, the proportion of epinephelid species ( $9 \%$ of total catch) appearing in catches from the PPA increased from $4 \%$ to $34 \%$. Additional analysis demonstrated that these changes were also consistent for absolute numbers of individuals caught, with the mean number of acanthurids caught per trip in PPAs declining from $8.5( \pm 1.1 \mathrm{SE})$ to 0.26 ( $\pm 0.26 \mathrm{SE})$, whereas epinephelids caught in PPAs increased from an average of $0.77( \pm 0.12 \mathrm{SE})$ to $2.42( \pm 1.2 \mathrm{SE})$ per trip (Append. 1, Fig. A3). These changes were not evident on reefs that were continuously open to fishing year round. Changes in catch composition through time also altered the overall lifehistory characteristics of the catch. By 2019 (10 years after the PPA implementation), landed catches had become 30\% more vulnerable (i.e., they comprised a greater proportion of species with vulnerable life-history characteristics) than they were in 2010, but remained relatively stable for catch from reefs open to continuous fishing (Fig. 4b; Append. 1, Table A6). The increase in vulnerable species demonstrates that fishers are now catching from the PPA proportionally more species with life-history characteristics that leave them prone to over-exploitation (i.e., those that are slower growing or older at first maturity) than they were previously. This was driven by both a decline in the relative abundance of low vulnerability acanthurids (mean vulnerability 26.9) and an increase in the relative abundance of high vulnerability epinephelid (mean vulnerability 55.2 ) in the catch. The increase in epinephelid catch was also largely driven by benthic species of the genus Cephalopholis (mean vulnerability 46.0) and Epinephelus (mean vulnerability 63.0). Notably, studies that have focused on single opening/harvesting events, rather than time series draw the conclusion that periodically harvested PPAs can support relatively higher biomass of lower vulnerability species (Jupiter et al. 2012, Januchowski-Hartley et al. 2014, Goetze et al. 2016). Also of note is that no other commonly caught fish families displayed an increase in catch despite 10 years of active management.

Catch data are a fisheries-dependent measure of population characteristics within an area, hence a range of factors can confound the relationship between what is caught and the status of the population (Maggs et al. 2016). These observed patterns could be due to (1) an increase in high vulnerability species,(2) a
Fig. 4. Catch composition over 10 years in a community employing partially protected areas (PPAs). A: Percent change in catch in the five most commonly caught fish families between open and partially protected reefs. Overall catch percentages for the top five fish families were: Acanthuridae $-30.5 \%$, Balistidae $-15.6 \%$, Scarinae $-6.6 \%$, Lutjanidae $-8.5 \%$, Epinephelidae $-9.1 \%$. B: Change in mean life-history vulnerability of catch between open and partially protected reefs. The green ribbon represents the estimated mean $( \pm 95 \%$ confidence interval) vulnerability per fishing trip of species caught within the periodically harvested PPA during opening periods. The blue ribbon represents catch vulnerability from fishing trips conducted at all other reefs surrounding the community. Points represent the means from each year $( \pm \mathrm{SE})$ that data were collected. The vulnerability of the catch ranges from 1 to 100, with higher values indicating greater vulnerability. Fish outlines on the y axis indicate the mean family level vulnerability of the top five most frequently caught fishes.
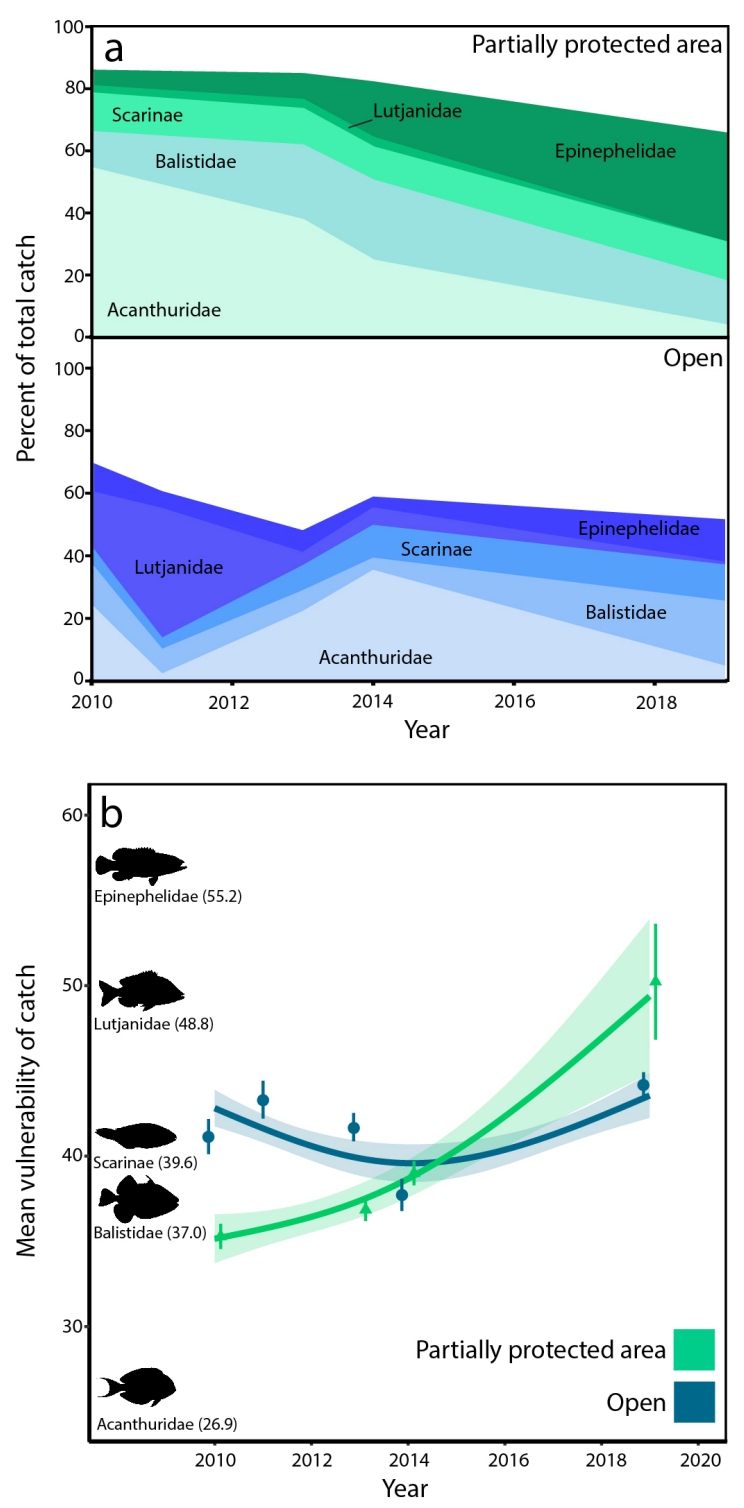
decrease in low vulnerability species, or (3) changes in fisher or fish behavior. Changes in catch of epinephelids (high vulnerability) and acanthurids (low vulnerability) may be due to changes in species abundance, either through stock recovery/loss or spill in (where individuals congregate in areas of less pressure) (Halpern et al. 2009). The targeting of smaller, benthic epinephelid species also suggests that the larger groupers may have been depleted prior to monitoring commencing, because these are generally the first species to be targeted on coral reefs (Coleman et al. 2000, de Mitcheson et al. 2020). If this was the case, then our findings are the product of a previous depletion of the largest, most vulnerable species, followed by the preferential selection and depletion of abundant low-vulnerability species, followed by a further switch to a more vulnerable, but previously underexploited group. Alternatively, changes may have occurred in the behavior of either fishers (e.g., change in gear use or perceived value of different species) or fish (e.g., change in catchability). For example, fishers could be actively targeting acanthurids within PPAs and/or passively targeting these species because changes in their behavior within the PPAs have made them relatively easy to catch. The limitations of using catch data in our study design prevent us from determining which of these explanations is most correct. Within this community, Cohen et al. (2013) also demonstrated that more fishing pressure can occur within a PPA in 2 weeks of opening than on adjacent continuously fished reefs over a whole year.

Regardless of the exact mechanism involved, if the goal of management is to sustainably use a resource, then changes in the life-history characteristics of the catch toward more vulnerable and longer-lived species implies a need to adaptively manage existing rules. In this case, adapting management rules will entail aligning effort, periodicity, and duration of PHC openings with the life-history characteristics of target species. There are two ways in which this could occur: first, if specific species are preferred, then periods of harvesting could be adjusted so as to align with the life-history of these species. Alternatively, if sociocultural regulations limit when harvesting occurs, then limiting harvest to specific taxa that are sustainable under that periodicity would be a viable alternative. Regardless of the preferred option, this emphasizes the adaptive nature of co-management, which could include increasing the duration of the closure period, decreasing the duration of the opening period, and/or adding further input or outputs controls on fishing effort and harvests. These feedback mechanisms that enable management to adapt to changing circumstances and stock characteristics through time will ultimately affect whether fishers experience relatively stable catches and catch rates over the long term (Armitage et al. 2008).

\section{CONCLUSIONS}

By examining nearly 3000 observations across three Pacific island nations, we bring to light three ways (productivity, catchability, and vulnerability) in which partial protection can influence the use and sustainability of natural resources. In the Tonga case study, we found that potential fisheries productivity was higher within PPAs, which suggests the volumes that fishers can harvest has been enhanced. In the Vanuatu case study, the implementation of PPAs made individual fish easier to catch by spear, which should endow fishers with greater harvesting efficiency. However, increased catchability can also make target species more susceptible to overfishing if additional controls on effort or catch are not in place. In the Solomon Islands case study, the composition of catch changed over a decade of management with partial protection and became dominated by species more intrinsically vulnerable to over-exploitation. Each of these vignettes illustrates distinct benefits and risks that can be managed through the adaptive aspects of co-management that respond to feedback and learning between resources and their users (Armitage et al. 2008).

We find that, although partial protection can confer clear benefits to fishers and fisheries, such as improvements in productivity and catchability, this management approach can also amplify certain risk. Size-dependent changes in fish behavior within PPAs are likely to induce a form of hyperstability, where yield and abundance become decoupled and catch may remain stable even while populations decline (Erisman et al. 2011, Hamilton et al. 2016, Maggs et al. 2016). Hyperstability is normally associated with aggregating species, such as the North Atlantic cod, a fishery that collapsed as a result (Rose and Kulka 1999). If fish behavior within PPAs changes faster than populations recover, with larger individuals within PPA boundaries becoming easier to catch than smaller fish beyond their boundaries, catches of large fish within PPAs may reflect increased tameness rather than abundance. This risks creating a false perception of growth and stock recovery where catch samples are not indicative of true population status. Second, the proportional increase in the catch of vulnerable species within PPAs over a decadal time-scale in itself suggests a potential risk, as the original objectives of management may not have planned for these changes.

Adaptive co-management of PPAs is one mechanism by which to mitigate the associated risks - that of hyperstability and overexploiting vulnerable species — while gaining the fisheries benefits of partial protection. The adaptive nature of management implies an iterative process of changing management practices based on new experiences and insights, such as monitoring, in order to steer the managed system toward a desired state (Cinner et al. 2019). In our cases, adaptively managing the risks associated with PPAs involves adjusting the periodicity of closures and openings (e.g., from once every 6 months to once every year, or from once every year to once every 2 years), as well as the intensity or methods of exploitation (e.g., bag or size limits, or restrictions to specific fishing methods), which in our case studies are typically changed based on social needs and demands instead of being grounded in sustainability of the resource being used (Cohen and Steenbergen 2015). Regardless of the exact mechanism involved, the long-term sustainability of PPAs is likely to be contingent on feedback mechanisms that enable management to adapt to changing circumstances and stock characteristics (Armitage et al. 2008).

Although our investigation into the benefits and risks of PPAs draws attention to how resource users will experience previously overlooked patterns of impact, there are several opportunities for future research to extend these insights through different research designs. First, all the PPAs we examined were part of established co-management systems with high legitimacy in the eyes of coastal communities and governments (Januchowski-Hartley et al. 2014, Cohen and Steenbergen 2015, Smallhorn-West et al. 2020a). If PPAs are designated, implemented, and enforced through top-down governance regimes where people feel that the rules are not created equitably (Mascia et al. 2010), or in locally 
managed systems with low legitimacy in the eyes of the government, or where management configurations are politically motivated so as to minimize overlap with resource use (Cockerell et al. 2020), then there may be different results as a consequence. Second, data limitations for this study meant that we could not employ a fully crossed sampling design, which would have enabled assessments of the precise mechanisms that drive changes in catch composition and population dynamics through time under partial protection. For example, in the Solomon Islands case study, simultaneous UVS and behavioral data would have enabled us to determine whether temporal trends in catch composition were due to changes in fish or fisher behavior, or changes in the ecosystem. Employing both fisheries dependent and independent data in the same location over decadal time scales to examine how these novel indicators interact would substantially improve our understanding of pathways to impact from marine management. We also acknowledge that observations from case studies tend to be strongly context dependent, and producing generalizable knowledge claims requires expanding observations and inferences from individual case studies beyond the spatial and/or temporal boundaries from which they were originally produced (Magliocca et al. 2018). Furthermore, we focused here on the fisheries outcomes of PPAs, but additional socioeconomic implications, as well as those pertaining to ecological integrity, function, and conservation outcomes, are also crucial to understand (Cinner et al. 2012). Lastly, quantifying levels of poaching and compliance, and their potential impacts on our findings, were beyond the scope of this study.

Finally, this study adds to the nuance and complexity of protected areas as a tool for the management of natural resources. We demonstrate that, in certain instances, partial protection is able to confer changes to fisheries performance-by changing ecosystem dynamics, how fish behave, and what people catch. But we also acknowledge the net effect of these changes is mixed, and further considerations are also needed beyond fisheries indicators. Even with positive fisheries benefits, other stakeholders in managed marine systems could be adversely affected by PPAs if those fisheries benefits come at the cost of nature. Conservation issues also continue to persist, and hence fully closed no-take managed protected areas must remain an integral part of spatial management, for both the positive conservation and fisheries impact they can supply (e.g., Harrison et al. 2012, Edgar et al. 2014). Lastly, only a small portion $(>1 \%)$ of the global area under management is done through bottom-up or co-management institutions (Gurney et al. 2021), and it remains unclear whether some or all of these indicators would be similarly affected by a top-down governance framework. With effective management, these vignettes suggest that co-managed or community oriented PPAs therefore can provide specific benefits for fisheries, but only so long as the potential risks are clearly understood.

\section{Responses to this article can be read online at:} https://www.ecologyandsociety.org/issues/responses. $\mathrm{php} / 13112$

\section{Acknowledgments:}

This work was funded by the Australian Research Council, the National Geographic Society, and the Australian Government through Australian Centre for International Agricultural Research (ACIAR) project FIS/2016/300. This work was undertaken as part of the Consultative Group for International Agricultural Research (CGIAR) Research Program on Fish Agri-Food Systems (FISH) led by WorldFish. The program is supported by contributors to the CGIAR Trust Fund.

\section{Data Availability:}

Data and code will be uploaded to PANGAEA, an online data repository, upon acceptance of the manuscript

\section{LITERATURE CITED}

Abesamis, R. A., A. L. Green, G. R. Russ, and C. R. L. Jadloc. 2014. The intrinsic vulnerability to fishing of coral reef fishes and their differential recovery in fishery closures. Reviews in Fish Biology and Fisheries 24(4):1033-1063. https://doi.org/10.1007/ $\underline{\text { s11160-014-9362-X }}$

Ahmadia, G. N., L. Glew, M. Provost, D. Gill, N. I. Hidayat, S. Mangubhai, Purwanto, and H. E. Fox. 2015. Integrating impact evaluation in the design and implementation of monitoring marine protected areas. Philosophical Transactions of the Royal Society B: Biological Sciences 370: : 20140275. https://doi. org/10.1098/rstb.2014.0275

Armitage, D., M. Marschke, and R. Plummer. 2008. Adaptive comanagement and the paradox of learning. Global Environmental Change 18(1):86-98. https://doi.org/10.1016/j.gloenvcha.2007.07.002

Ban, N. C., G. G. Gurney, N. A. Marshall, C. K. Whitney, M. Mills, S. Gelcich, N. J. Bennett, M. C. Meehan, C. Butler, S. Ban, T. C. Tran, M. E. Cox, and S. J. Breslow. 2019. Well-being outcomes of marine protected areas. Nature Sustainability 2:524-532. https://doi.org/10.1038/s41893-019-0306-2

Brock, R. E. 1985. Preliminary study of the feeding habits of pelagic fish around Hawaiian fish aggregation devices or can fish aggregation devices enhance local fisheries productivity? Bulletin of Marine Science 37(1):40-49.

Brockington, D., and K. Schmidt-Soltau. 2017. The social and environmental impacts of wilderness and development. Oryx 38 (2):140-142. https://doi.org/10.1017/S0030605304000250

Carvalho, P. G., J. Goetze, S. D. Jupiter, J. Claudet, F. A. J. Hartley, and R. Weeks. 2019. Optimized fishing through periodically harvested closures. Journal of Applied Ecology 56(8):1927-1936. https://doi.org/10.1111/1365-2664.13417

Cheung, W. W. L., T. J. Pitcher, and D. Pauly. 2005. A fuzzy logic expert system to estimate intrinsic extinction vulnerabilities of marine fishes to fishing. Biological Conservation 124(1):97-111. https://doi.org/10.1016/j.biocon.2005.01.017

Cheung, W. W. L., R. Watson, T. Morato, T. J. Pitcher, and D. Pauly. 2007. Intrinsic vulnerability in the global fish catch. Marine 
Ecology Progress Series 333:1-12. https://doi.org/10.3354/ meps333001

Cinner, J. E., J. D. Lau, A. G. Bauman, D. A. Feary, F. A. Januchowski-hartley, C. A. Rojas, and M. L. Barnes. 2019. Sixteen years of social and ecological dynamics reveal challenges and opportunities for adaptive management in sustaining the commons. Proceedings of the National Academy of Sciences 116 (52):26474-26483. https://doi.org/10.1073/pnas.1914812116

Cinner, J. E., E. Maire, C. Huchery, M. A. MacNeil, N. A. J. Graham, C. Mora, T. R. McClanahan, M. L. Barnes, J. N. Kittinger, and C. C. Hicks. 2018. Gravity of human impacts mediates coral reef conservation gains. Proceedings of the National Academy of Sciences 115(27):E6116-E6125. https://doi. org/10.1073/pnas.1708001115

Cinner, J., M. J. Marnane, T. R. McClanahan, and G. R. Almany. 2006. Periodic closures as adaptive coral reef management in the Indo-Pacific. Ecology and Society 11(1): 31. https://doi. org/10.5751/ES-01618-110131

Cinner, J. E., T. R. Mcclanahan, M. A. Macneil, N. A. J. Graham, T. M. Daw, A. Mukminin, D. A. Feary, A. L. Rabearisoa, A. Wamukota, N. Jiddawi, and S. J. Campbell. 2012. Comanagement of coral reef social-ecological systems. Proceedings of the National Academy of Sciences 109(14):5219-5222. https://doi. org/10.1073/pnas.1121215109

Cinner, J. E., J. Zamborain-Mason, G. G. Gurney, N. A. J. Graham, M. A. MacNeil, A. S. Hoey, C. Mora, S. Villéger, E. Maire, T. R. McClanahan, J. M. Maina, J. N. Kittinger, C. C. Hicks, S. D'Agata, C. Huchery, M. L. Barnes, D. A. Feary, I. D. Williams, M. Kulbicki, L. Vigliola, L. Wantiez, G. J. Edgar, R. D. Stuart-Smith, S. A. Sandin, A. L. Green, M. Beger, A. M. Friedlander, S. K. Wilson, E. Brokovich, A. J. Brooks, J. J. CruzMotta, D. J. Booth, P. Chabanet, M. Tupper, S. C. A. Ferse, U. R. Sumaila, M. J. Hardt, and D. Mouillot. 2020. Meeting fisheries, ecosystem function, and biodiversity goals in a human-dominated world. Science 368(6488):307-311. https://doi.org/10.1126/ $\underline{\text { science. } \operatorname{aax} 9412}$

Cockerell, B., R. L. Pressey, A. Grech, J. G. Álvarez-Romero, T. Ward, and R. Devillers. 2020. Representation does not necessarily reduce threats to biodiversity: Australia's Commonwealth marine protected area system, 2012-2018. Biological Conservation 252: 108813. https://doi.org/10.1016/j.biocon.2020.108813

Cohen, P. J., and T. J. Alexander. 2013. Catch rates, composition and fish size from reefs managed with periodically-harvested closures. PLoS ONE 8(9): e73383. https://doi.org/10.1371/ journal.pone. 0073383

Cohen, P. J., J. E. Cinner, and S. Foale. 2013. Fishing dynamics associated with periodically harvested marine closures. Global Environmental Change 23(6):1702-1713. https://doi.org/10.1016/ j.gloenvcha.2013.08.010

Cohen, P. J., and S. J. Foale. 2013. Sustaining small-scale fisheries with periodically harvested marine reserves. Marine Policy 37:278-287. https://doi.org/10.1016/j.marpol.2012.05.010

Cohen, P. J., and D. J. Steenbergen. 2015. Social dimensions of local fisheries co-management in the Coral Triangle. Environmental Conservation 42(3):278-288. https://doi.org/10.1017/ $\underline{\mathrm{S} 0376892914000423}$
Cohen, P., S. Tapala, A. Rikio, E. Kukiti, and F. Sori. 2014. Developing a common understanding of taxonomy for fisheries management in north Vella Lavella, Solomon Islands. SPC Traditional Marine Resource Management and Knowledge Information Bulletin 33(June):3-12.

Coleman, F. C., C. C. Koenig, G. R. Huntsman, J. A. Musick, A. M. Eklund, J. C. McGovern, G. R. Sedberry, R. W. Chapman, and C. B. Grimes. 2000. Long-lived reef fishes: the groupersnapper complex. Fisheries 25(3):14-21. https://doi.org/10.1577/1548-8446 (2000)025<0014:LRF>2.0.CO;2

de Mitcheson, Y. J. S., C. Linardich, J. P. Barreiros, G. M. Ralph, A. Aguilar-Perera, P. Afonso, B. E. Erisman, D. A. Pollard, S. T. Fennessy, and A. A. Bertoncini. 2020. Valuable but vulnerable: over-fishing and under-management continue to threaten groupers so what now? Marine Policy 116:103909. https://doi. org/10.1016/j.marpol.2020.103909

Edgar, G. J., R. D. Stuart-Smith, T. J. Willis, S. Kininmonth, S. C. Baker, S. Banks, N. S. Barrett, M. A. Becerro, A. T. F. Bernard, and J. Berkhout. 2014. Global conservation outcomes depend on marine protected areas with five key features. Nature 506 (7487):216-220. https://doi.org/10.1038/nature13022

Erisman, B. E., L. G. Allen, J. T. Claisse, D. J. Pondella, E. F. Miller, and J. H. Murray. 2011. The illusion of plenty: hyperstability masks collapses in two recreational fisheries that target fish spawning aggregations. Canadian Journal of Fisheries and Aquatic Sciences 68(10):1705-1716. https://doi.org/10.1139/ $\underline{\mathrm{f2011-090}}$

Ferraro, P. J., and M. M. Hanauer. 2011. Protecting ecosystems and alleviating poverty with parks and reserves: "win-win" or tradeoffs? Environmental and Resource Economics 48:269-286. https://doi.org/10.1007/s10640-010-9408-Z

Finney, B. P., I. Gregory-Eaves, M. S. V. Douglas, and J. P. Smol. 2002. Fisheries productivity in the northeastern Pacific Ocean over the past 2,200 years. Nature 416(6882):729-733. https://doi. org/10.1038/416729a

Foale, S., P. Cohen, S. Januchowski-Hartley, A. Wenger, and M. Macintyre. 2011. Tenure and taboos: origins and implications for fisheries in the Pacific. Fish and Fisheries 12(4):357-369. https:// doi.org/10.1111/j.1467-2979.2010.00395.x

Giakoumi, S., C. Scianna, J. Plass-Johnson, F. Micheli, K. Grorud-Colvert, P. Thiriet, J. Claudet, G. Di Carlo, A. Di Franco, S. D. Gaines, J. A. García-Charton, J. Lubchenco, J. Reimer, E. Sala, and P. Guidetti. 2017. Ecological effects of full and partial protection in the crowded Mediterranean Sea: a regional metaanalysis. Scientific Reports 7(1):1-12. https://doi.org/10.1038/ s41598-017-08850-W

Goetze, J. S., J. Claudet, F. Januchowski-Hartley, T. J. Langlois, S. K. Wilson, C. White, R. Weeks, and S. D. Jupiter. 2018. Demonstrating multiple benefits from periodically harvested fisheries closures. Journal of Applied Ecology 55(3):1102-1113. https://doi.org/10.1111/1365-2664.13047

Goetze, J. S., F. A. Januchowski-Hartley, J. Claudet, T. J. Langlois, S. K. Wilson, and S. D. Jupiter. 2017. Fish wariness is a more sensitive indicator to changes in fishing pressure than abundance, length or biomass. Ecological Applications 27(4):1178-1189. https://doi.org/10.1002/eap.1511 
Goetze, J., T. Langlois, J. Claudet, F. Januchowski-Hartley, and S. D. Jupiter. 2016. Periodically harvested closures require full protection of vulnerable species and longer closure periods. Biological Conservation 203:67-74. https://doi.org/10.1016/j. biocon.2016.08.038

Gurney, G. G., E. S. Darling, G. N. Ahmadia, V. N. Agostini, N. C. Ban, J. Blythe, J. Claudet, G. Epstein, Estradivari, A. HimesCornell, H. D. Jonas, D. Armitage, S. J. Campbell, C. Cox, W. R. Friedman, D. Gill, P. Lestari, S. Mangubhai, E. McLeod, N. A. Muthiga, J. Naggea, R. Ranaivoson, A. Wenger, I. Yulianto, and S. D. Jupiter. 2021. Biodiversity needs every tool in the box: use OECMs. Nature 595(7869):646-649. https://doi.org/10.1038/ d41586-021-02041-4

Haasnoot, M., R. Biesbroek, J. Lawrence, V. Muccione, R. Lempert, and B. Glavovic. 2020. Defining the solution space to accelerate climate change adaptation. Regional Environmental Change 20(2):1-5. https://doi.org/10.1007/s10113-020-01623-8

Halpern, B. S., C. J. Klein, C. J. Brown, M. Beger, H. S. Grantham, S. Mangubhai, M. Ruckelshaus, V. J. Tulloch, M. Watts, and C. White. 2013. Achieving the triple bottom line in the face of inherent trade-offs among social equity, economic return, and conservation. Proceedings of the National Academy of Sciences 110(15):6229-6234. https://doi.org/10.1073/pnas.1217689110

Halpern, B. S., S. E. Lester, and J. B. Kellner. 2009. Spillover from marine reserves and the replenishment of fished stocks. Environmental Conservation 36(4):268-276. https://doi.org/10.1017/ $\underline{\mathrm{S} 0376892910000032}$

Hamilton, R. J., G. R. Almany, D. Stevens, M. Bode, J. Pita, N. A. Peterson, and J. H. Choat. 2016. Hyperstability masks declines in bumphead parrotfish (Bolbometopon muricatum) populations. Coral Reefs 35(3):751-763. https://doi.org/10.1007/s00338-016-1441-0

Harrison, H. B., D. H. Williamson, R. D. Evans, G. R. Almany, S. R. Thorrold, G. R. Russ, K. A. Feldheim, L. van Herwerden, S. Planes, and M. Srinivasan. 2012. Larval export from marine reserves and the recruitment benefit for fish and fisheries. Current Biology 22(11):1023-1028. https://doi.org/10.1016/j.cub.2012.04.008

Ho, D., K. Imai, G. King, E. Stuart, and A. Whitworth. 2018. MatchIt: nonparametric preprocessing for parametric causal inference description. Journal of Statistical Software 42(8):1-28. https://doi.org/10.18637/jss.v042.i08

Januchowski-Hartley, F. A., J. E. Cinner, and N. A. J. Graham. 2014. Fishery benefits from behavioural modification of fishes in periodically harvested fisheries closures. Aquatic Conservation 24(6):790:777-790. https://doi.org/10.1002/aqc.2388

Januchowski-Hartley, F. A., N. A. J. Graham, J. E. Cinner, and G. R. Russ. 2013. Spillover of fish naïveté from marine reserves. Ecology Letters 16(2):191-197. https://doi.org/10.1111/ele.12028

Januchowski-Hartley, F. A., N. A. J. Graham, J. E. Cinner, and G. R. Russ. 2015. Local fishing influences coral reef fish behavior inside protected areas of the Indo-Pacific. Biological Conservation 182:8-12. https://doi.org/10.1016/j.biocon.2014.11.024

Januchowski-Hartley, F. A., K. L. Nash, and R. J. Lawton. 2012. Influence of spear guns, dive gear and observers on estimating fish flight initiation distance on coral reefs. Marine Ecology Progress Series 469:113-119. https://doi.org/10.3354/meps09971

Jennings, S., and N. V. C. Polunin. 1996. Effects of fishing effort and catch rate upon the structure and biomass of Fijian reef fish communities. Journal of Applied Ecology:400-412. https://doi. org/10.2307/2404761

Joppa, L. N., and A. Pfaff. 2011. Global protected area impacts. Proceedings of the Royal Society B: Biological Sciences 278 (1712):1633-1638. https://doi.org/10.1098/rspb.2010.1713

Jupiter, S. D., P. J. Cohen, R. Weeks, A. Tawake, and H. Govan. 2014. Locally-managed marine areas: multiple objectives and diverse strategies. Pacific Conservation Biology 20(2):165-179. https://doi.org/10.1071/PC140165

Jupiter, S. D., R. Weeks, A. P. Jenkins, D. P. Egli, and A. Cakacaka. 2012. Effects of a single intensive harvest event on fish populations inside a customary marine closure. Coral Reefs 31 (2):321-334. https://doi.org/10.1007/s00338-012-0888-X

Lennox, R. J., J. Alós, R. Arlinghaus, A. Horodysky, T. Klefoth, C. T. Monk, and S. J. Cooke. 2017. What makes fish vulnerable to capture by hooks? A conceptual framework and a review of key determinants. Fish and Fisheries 18(5):986-1010. https://doi. org/10.1111/faf.12219

Lester, S. E., and B. S. Halpern. 2008. Biological responses in marine no-take reserves versus partially protected areas. Marine Ecology Progress Series 367:49-56. https://doi.org/10.3354/ $\underline{\text { meps07599 }}$

MacNeil, M. A., N. A. J. Graham, J. E. Cinner, S. K. Wilson, I. D. Williams, J. Maina, S. Newman, A. M. Friedlander, S. Jupiter, and N. V. C. Polunin. 2015. Recovery potential of the world's coral reef fishes. Nature 520(7547):341-344. https://doi. org/10.1038/nature14358

Maggs, J. Q., B. Q. Mann, W. M. Potts, and S. W. Dunlop. 2016. Traditional management strategies fail to arrest a decline in the catch-per-unit-effort of an iconic marine recreational fishery species with evidence of hyperstability. Fisheries Management and Ecology 23(3-4):187-199. https://doi.org/10.1111/fme.12125

Magliocca, N. R., E. C. Ellis, G. R. Allington, A. de Bremond, J. DellAngelo, O. Mertz, P. Messerli, P. Meyfroidt, R. Seppelt, and P. H. Verburg. 2018. Closing global knowledge gaps: producing generalized knowledge from case studies of social-ecological systems. Global Environmental Change 50:1-14. https://doi. org/10.1016/j.gloenvcha.2018.03.003

Mascia, M. B., C. A. Claus, and R. Naidoo. 2010. Impacts of marine protected areas on fishing communities. Conservation Biology 24(5):1424-1429. https://doi.org/10.1111/j.1523-1739.2010.01523. $\underline{x}$

McClanahan, T. R., C. A. Abunge, and J. E. Cinner. 2012. Heterogeneity in fishers' and managers' preferences towards management restrictions and benefits in Kenya. Environmental Conservation 39(4):357-369. https://doi.org/10.1017/S0376892912000197

Morais, R. A., and D. R. Bellwood. 2019. Pelagic subsidies underpin fish productivity on a degraded coral reef. Current Biology 29(9):1521-1527. https://doi.org/10.1016/j.cub.2019.03.044 
Morais, R. A., and D. R. Bellwood. 2020. Principles for estimating fish productivity on coral reefs. Coral Reefs 39(5):1221-1231. https://doi.org/10.1007/s00338-020-01969-9

Morais, R. A., S. R. Connolly, and D. R. Bellwood. 2020. Human exploitation shapes productivity-biomass relationships on coral reefs. Global Change Biology 26(3):1295-1305. https://doi. org/10.1111/gcb.14941

Morais, R. A., A. C. Siqueira, P. F. Smallhorn-West, and D. R. Bellwood. 2021. Spatial subsidies drive sweet spots of tropical marine biomass production. PLoS Biology 19(11): e3001435. https://doi.org/10.1371/journal.pbio.3001435

Olmos, A., and P. Govindasamy. 2015. Propensity scores: a practical introduction using R. Journal of Multidisciplinary Evaluation 11(25):68-88.

Parks, J. 2017. Baseline socioeconomic survey of the Vava'u special management areas as a component of the Tonga climate resilience sector. Report to the Asian Development Bank, Mandaluyong, Metro Manila, Philippines.

R Core Team. 2016. R: a language and environment for statistical computing. R Foundation for Statistical Computing. 2017. Vienna, Austria.

Robinson, J., N. A. J. Graham, J. E. Cinner, G. R. Almany, and P. Waldie. 2015. Fish and fisher behaviour influence the vulnerability of groupers (Epinephelidae) to fishing at a multispecies spawning aggregation site. Coral Reefs 34 (2):371-382. https://doi.org/10.1007/s00338-014-1243-1

Rose, G. A., and D. W. Kulka. 1999. Hyperaggregation of fish and fisheries: how catch-per-unit-effort increased as the northern cod (Gadus morhua) declined. Canadian Journal of Fisheries and Aquatic Sciences 56(S1):118-127. https://doi.org/10.1139/f99-207

Rosenbaum, P. R., and D. B. Rubin. 1983. The central role of the propensity score in observational studies for causal effects. Biometrika 70(1):41-55. https://doi.org/10.21236/ADA114514

Sala, E., and S. Giakoumi. 2018. No-take marine reserves are the most effective protected areas in the ocean. ICES Journal of Marine Science 75(3):1166-1168. https://doi.org/10.1093/icesjms/ $\underline{\text { fsx059 }}$

Sbragaglia, V., L. Morroni, L. Bramanti, B. Weitzmann, R. Arlinghaus, and E. Azzurro. 2018. Spearfishing modulates flight initiation distance of fishes: the effects of protection, individual size, and bearing a speargun. ICES Journal of Marine Science 75 (5):1779-1789. https://doi.org/10.1093/icesims/fsy059

Smallhorn-West, P. F., S. E. Gordon, A. C. Dempsey, S. J. Purkis, S. Malimali, T. Halafihi, P. C. Southgate, T. C. L. Bridge, R. L. Pressey, and G. P. Jones. 2019. Tongan socio-environmental spatial layers for marine ecosystem management. Pacific Conservation Biology 27:86-92. https://doi.org/10.1071/PC19032

Smallhorn-West, P. F., J. Sheehan, S. Malimali, T. Halafihi, T. C. L. Bridge, R. L. Pressey, and G. P. Jones. 2020a. Incentivizing comanagement for impact: mechanisms driving the successful national expansion of Tonga's special management area program. Conservation Letters 13(6): e12742. https://doi.org/10.1111/ conl.12742
Smallhorn-West, P. F., K. Stone, D. Ceccarelli, S. MaliMali, T. Halafihi, T. Bridge, R. Pressey, and G. Jones. 2020b. Community management yields positive impacts for coastal fisheries reosurces and biodiversity conservation. Conservation Letters 13(6): e12755. https://doi.org/10.1111/conl.12755

Tran, D. S. C., K. A. Langel, M. J. Thomas, and D. T. Blumstein. 2016. Spearfishing-induced behavioral changes of an unharvested species inside and outside a marine protected area. Current Zoology 62(1):39-44. https://doi.org/10.1093/cz/zov006

Turnbull, J. W., E. L. Johnston, and G. F. Clark. 2021. Evaluating the social and ecological effectiveness of partially protected marine areas. Conservation Biology 35(3):921-932. https://doi. org/10.1111/cobi.13677

Visconti, P., M. Bakkenes, R. J. Smith, L. Joppa, and R. E. Sykes. 2015. Socio-economic and ecological impacts of global protected area expansion plans. Philosophical Transactions of the Royal Society B: Biological Sciences 370: 20140284. https://doi. org/10.1098/rstb.2014.0284

Waldron, A., V. Adams, J. Allan, A. Arnell, G. Asner, S. Atkinson, A. Baccini, J. Baillie, A. Balmford, and J. Austin Beau. 2020. Protecting $30 \%$ of the planet for nature: costs, benefits and economic implications. Conservation Research Institute, University of Cambridge, Cambridge, UK.

Welcomme, R. L., and D. M. Bartley. 1998. Current approaches to the enhancement of fisheries. Fisheries Management and Ecology 5(5):351-382. https://doi.org/10.1046/j.1365-2400.1998.550351. $\underline{\mathrm{X}}$

Zupan, M., E. Fragkopoulou, J. Claudet, K. Erzini, B. Horta e Costa, and E. J. Gonçalves. 2018. Marine partially protected areas: drivers of ecological effectiveness. Frontiers in Ecology and the Environment 16(7):381-387. https://doi.org/10.1002/fee.1934 


\section{Appendix}

Table A1. Covariate balance pre- and post-matching for surveys evaluating Tonga's Special Management Area program. Values over 25 suggest imbalanced covariates. Chi-squared tests using the Xbalance package were performed to determine whether at least one covariate was unbalanced pre and post matching.

\begin{tabular}{lcc}
\hline \hline Variable & Pre-matching & Post-matching \\
\hline Surveyor 1 & 42.20 & NaN \\
Surveyor 2 & 19.61 & 13.85 \\
Surveyor 3 & 12.61 & 19.18 \\
Surveyor 4 & 41.29 & 6.45 \\
Habitat -Fringing & 9.47 & 7.39 \\
Habitat - Semi-exposed & 6.40 & 6.90 \\
Habitat - Exposed & 3.03 & 0.15 \\
Island group - Vava'u & 91.98 & 16.85 \\
Island group - Ha'apai & 88.91 & 15.14 \\
Island group - Tongatapu & 0.00 & 1.08 \\
Fishing pressure & 35.35 & 15.99 \\
Wave energy & 2.22 & 21.64 \\
Depth & 36.69 & 13.46 \\
Slope & 24.62 & 17.61 \\
Habitat rugosity & 26.12 & 22.97 \\
Coral cover & 14.99 & 12.55 \\
\hline \hline
\end{tabular}


Table A2. Covariate values pre- and post-matching for surveys evaluating Tonga's Special Management Area program. The first column lists the covariates used to match control and treatment transects, and for each covariate match statistics are provided before and after matching, indicated in the 'unmatched' and 'matched' rows, to show how well the matching model performed. The third and fourth column present mean covariate values for treatment and control transects. The fifth column shows the mean difference between FHR and control means. The sixth and seventh column respectively show mean and maximum differences in each covariate Quantile - Quantile (QQ plot), with lower values indicating a better match. The lower table shows the total, matched and unmatched number of control and treatment transects respectively following the matching procedure.

\begin{tabular}{|c|c|c|c|c|c|c|}
\hline Variable & & $\begin{array}{c}\text { Treatment } \\
\text { mean }\end{array}$ & $\begin{array}{c}\text { Control } \\
\text { mean }\end{array}$ & $\begin{array}{l}\text { std. } \\
\text { mean } \\
\text { diff. }\end{array}$ & $\begin{array}{c}\text { mean } \\
\text { eQQ } \\
\text { diff. }\end{array}$ & $\begin{array}{l}\max \\
\text { eQQ } \\
\text { diff. }\end{array}$ \\
\hline \multirow[t]{2}{*}{ Depth } & unmatched & 5.46 & 6.34 & -0.87 & 0.88 & 3 \\
\hline & matched & 5.41 & 5.88 & -0.48 & 0.58 & 2.30 \\
\hline \multirow[t]{2}{*}{ Fishing pressure } & unmatched & 17.00 & 22.36 & -5.36 & 6.09 & 37.41 \\
\hline & matched & 17.12 & 18.24 & -1.13 & 5.17 & 26.62 \\
\hline \multirow[t]{2}{*}{ Habitat - Fringing } & unmatched & 0.30 & 0.34 & -0.04 & 0.04 & 1.00 \\
\hline & matched & 0.31 & 0.31 & 0.46 & 0.09 & 1.00 \\
\hline \multirow{4}{*}{$\begin{array}{l}\text { Habitat - Semi- } \\
\text { exposed } \\
\text { Habitat Exposed }\end{array}$} & unmatched & 0.33 & 0.30 & 0.00 & 0.03 & 1.00 \\
\hline & matched & 0.33 & 0.33 & 0.00 & 0.08 & 1.00 \\
\hline & unmatched & 0.36 & 0.35 & 0.01 & 0.02 & 1.00 \\
\hline & matched & 0.37 & 0.37 & 0.00 & 0.09 & 1.00 \\
\hline \multirow[t]{2}{*}{ Island Ha'apai } & unmatched & 0.68 & 0.27 & 0.40 & 0.40 & 1.00 \\
\hline & matched & 0.68 & 0.68 & 0.00 & 0.15 & 1.00 \\
\hline \multirow{2}{*}{ Island Tongatapu } & unmatched & 0.15 & 0.15 & 0.00 & 0.00 & 0.00 \\
\hline & matched & 0.15 & 0.15 & 0.00 & 0.09 & 1.00 \\
\hline \multirow[t]{2}{*}{ Island Vava'u } & unmatched & 0.18 & 0.58 & -0.41 & 0.41 & 1.00 \\
\hline & matched & 0.18 & 0.18 & 0.00 & 0.14 & 1.00 \\
\hline \multirow[t]{2}{*}{ Live coral cover } & unmatched & 19.68 & 17.56 & 2.12 & 2.53 & 21.31 \\
\hline & matched & 19.73 & 19.87 & -0.14 & 0.85 & 5.40 \\
\hline \multirow[t]{2}{*}{ Habitat rugosity } & unmatched & 2.76 & 3.03 & -0.26 & 0.26 & 1.00 \\
\hline & matched & 2.77 & 2.83 & -0.06 & 0.20 & 1.00 \\
\hline \multirow{2}{*}{ Slope } & unmatched & 2.62 & 2.85 & -0.24 & 0.24 & 1.00 \\
\hline & matched & 2.62 & 2.74 & -0.12 & 0.21 & 1.00 \\
\hline \multirow[t]{2}{*}{ Surveyor 1} & unmatched & 0.00 & 0.08 & -0.08 & 0.08 & 1.00 \\
\hline & matched & 0.00 & 0.00 & 0.00 & 0.00 & 0.00 \\
\hline \multirow[t]{2}{*}{ Surveyor 2} & unmatched & 0.06 & 0.11 & -0.05 & 0.06 & 1.00 \\
\hline & matched & 0.05 & 0.05 & 0.00 & 0.03 & 1.00 \\
\hline \multirow[t]{2}{*}{ Surveyor 3} & unmatched & 0.13 & 0.17 & -0.05 & 0.05 & 1.00 \\
\hline & matched & 0.13 & 0.13 & 0.00 & 0.05 & 1.00 \\
\hline \multirow[t]{2}{*}{ Surveyor 4} & unmatched & 0.82 & 0.64 & 0.18 & 0.18 & 1.00 \\
\hline & matched & 0.82 & 0.82 & 0.00 & 0.01 & 1.00 \\
\hline \multirow[t]{2}{*}{ Wave energy } & unmatched & 341.59 & 330.38 & 11.21 & 91.26 & 1450.56 \\
\hline & matched & 337.48 & 285.21 & 52.27 & 85.63 & 951.00 \\
\hline \multirow{5}{*}{$\begin{array}{l}\text { All transects } \\
\text { Matched } \\
\text { transects } \\
\text { Unmatched } \\
\text { transects }\end{array}$} & Control & Treated & & & & \\
\hline & 1308 & 327 & & & & \\
\hline & 377 & 324 & & & & \\
\hline & & & & & & \\
\hline & 931 & 3 & & & & \\
\hline
\end{tabular}


Table A3. Estimated regression parameters, standard error, $z$-values and $P$-values for logistic GLMs of Acanthuridae and Scarinae probability of capture.

\begin{tabular}{llcccc}
\hline Family & & Estimate & \multicolumn{1}{l}{ SE } & z value & $P$-value \\
\hline Acanthuridae & Intercept & -1.150 & 0.379 & 3.038 & $<0.01$ \\
& Size (TL) & -0.991 & 0.419 & -2.365 & $<0.05$ \\
& No-take zone & 2.942 & 0.560 & 5.255 & $<0.001$ \\
& PPA & 1.360 & 0.488 & 2.788 & $<0.01$ \\
& Size:No-take & & & & \\
& zone & 0.671 & 0.537 & 1.250 & 0.211 \\
& Size:PPA & 0.300 & 0.557 & 0.539 & 0.590 \\
Scarinae & Intercept & -2.137 & 0.473 & -4.517 & $<0.001$ \\
& Size (TL) & -0.767 & 0.690 & -1.112 & 0.266 \\
& No-take zone & 2.666 & 0.507 & 5.256 & $<0.001$ \\
& PPA & 1.671 & 0.524 & 3.186 & $<0.01$ \\
& Size:No-take & & & & \\
& zone & 0.458 & 0.713 & 0.643 & 0.520 \\
& Size:PPA & -0.026 & 0.788 & -0.033 & 0.974 \\
\hline \hline
\end{tabular}


Table A4. Model outputs assessing target and total biomass and productivity impacts from no-take and restricted access areas in Tonga's Special Management Area program. Cl indicates 95\% confidence intervals from mixed effect models with Transect and Community included as random factors. PPA = Partially protected area

\begin{tabular}{|c|c|c|c|c|c|c|c|}
\hline Response & Management & Predictors & $\begin{array}{c}\text { Marginal } \\
R^{2} \\
\end{array}$ & $\begin{array}{c}\text { onditional } \\
R^{2} \\
\end{array}$ & Estimates & $\mathrm{Cl}$ & $p$ \\
\hline \multirow{4}{*}{$\begin{array}{l}\text { Target species } \\
\text { biomass }\end{array}$} & No-take & (Intercept) & 0.186 & 0.396 & 1.81 & $1.55-2.11$ & $<0.001$ \\
\hline & & $\begin{array}{l}\text { Treatment } \\
\text { [Counterfactual] }\end{array}$ & & & 0.65 & $0.59-0.71$ & $<0.001$ \\
\hline & $\overline{\mathrm{PPA}}$ & (Intercept) & 0.030 & 0.641 & 0.57 & $0.33-0.97$ & 0.038 \\
\hline & & $\begin{array}{l}\text { Treatment } \\
\text { [Counterfactual] }\end{array}$ & & & 0.74 & $0.39-1.40$ & 0.356 \\
\hline \multirow{3}{*}{$\begin{array}{l}\text { Target species } \\
\text { productivity }\end{array}$} & No-take & (Intercept) & 0.146 & 0.510 & 1.20 & $0.90-1.61$ & 0.218 \\
\hline & & $\begin{array}{l}\text { Treatment } \\
\text { [Counterfactual] }\end{array}$ & & & 0.63 & $0.46-0.88$ & 0.007 \\
\hline & $\overline{\mathrm{PPA}}$ & $\begin{array}{l}\text { (Intercept) } \\
\text { Treatment } \\
\text { [Counterfactual] }\end{array}$ & 0.130 & 0.621 & $\begin{array}{l}1.06 \\
0.60\end{array}$ & $\begin{array}{l}0.77-1.46 \\
0.37-0.97\end{array}$ & $\begin{array}{l}0.712 \\
\mathbf{0 . 0 3 8}\end{array}$ \\
\hline \multirow{4}{*}{$\begin{array}{l}\text { Total species } \\
\text { biomass }\end{array}$} & No-take & (Intercept) & 0.231 & 0.629 & 0.96 & $0.67-1.39$ & 0.848 \\
\hline & & $\begin{array}{l}\text { Treatment } \\
\text { [Counterfactual] }\end{array}$ & & & 0.50 & $0.29-0.86$ & 0.012 \\
\hline & $\overline{\mathrm{PPA}}$ & (Intercept) & 0.048 & 0.613 & 0.71 & $0.44-1.15$ & 0.164 \\
\hline & & $\begin{array}{l}\text { Treatment } \\
\text { [Counterfactual] }\end{array}$ & & & 0.72 & $0.41-1.25$ & 0.238 \\
\hline \multirow{3}{*}{$\begin{array}{l}\text { Total species } \\
\text { productivity }\end{array}$} & No-take & (Intercept) & 0.208 & 0.558 & 1.75 & $1.41-2.17$ & $<0.001$ \\
\hline & & $\begin{array}{l}\text { Treatment } \\
\text { [Counterfactual] }\end{array}$ & & & 0.64 & $0.50-0.81$ & $<0.001$ \\
\hline & $\overline{\mathrm{PPA}}$ & $\begin{array}{l}\text { (Intercept) } \\
\text { Treatment } \\
\text { [Counterfactual] }\end{array}$ & 0.159 & 0.623 & $\begin{array}{l}1.53 \\
0.61\end{array}$ & $\begin{array}{l}1.12-2.10 \\
0.38-0.98\end{array}$ & $\begin{array}{l}0.008 \\
0.043\end{array}$ \\
\hline
\end{tabular}


Table A5. Model output of logistic binomial regression of probability of capture with fish size. SE indicates standard error of model coefficients. Mean are the results for a maximum effective range of $337 \mathrm{~cm}$ (the mean distance reported in Januchowski-Hartley et al. 2014), High are results for the highest estimated effective range $(360 \mathrm{~cm})$ while Low are results for lowest estimated range $(305 \mathrm{~cm})$. Statistically significant $(p<0.05)$ coefficients are indicated in bold. PPA $=$ partially protected area

\begin{tabular}{|c|c|c|c|c|c|c|c|c|}
\hline \multirow{2}{*}{$\begin{array}{l}\text { Taxonomic } \\
\text { grouping }\end{array}$} & \multirow[b]{2}{*}{ Management } & \multirow[b]{2}{*}{ Parameter } & \multicolumn{3}{|c|}{ Mean } & \multicolumn{3}{|c|}{ High } \\
\hline & & & Estimate & $S E$ & $p$ & Estimate & $S E$ & $p$ \\
\hline \multirow[t]{6}{*}{ Acanthuridae } & No-take & Intercept & 3.820 & 2.181 & 0.080 & 4.432 & 2.478 & 0.074 \\
\hline & & Total length & -0.094 & 0.098 & 0.338 & -0.104 & 0.110 & 0.344 \\
\hline & PPA & Intercept & 4.582 & 2.399 & 0.056 & 7.576 & 2.708 & 0.005 \\
\hline & & Total length & -0.202 & 0.107 & 0.059 & -0.310 & 0.118 & 0.008 \\
\hline & Fished & Intercept & 5.121 & 2.531 & 0.043 & 7.894 & 2.573 & 0.002 \\
\hline & & Total length & -0.290 & 0.123 & 0.018 & -0.379 & 0.120 & 0.002 \\
\hline \multirow[t]{6}{*}{ Scarinae } & No-take & Intercept & 5.387 & 2.013 & 0.007 & 8.590 & 2.711 & 0.002 \\
\hline & & Total length & -0.145 & 0.720 & 0.043 & -0.238 & 0.092 & 0.010 \\
\hline & PPA & Intercept & 4.053 & 2.127 & 0.058 & 5.620 & 2.122 & 0.008 \\
\hline & & Total length & -0.172 & 0.083 & 0.038 & -0.216 & 0.082 & 0.008 \\
\hline & Fished & Intercept & 4.292 & 4.751 & 0.366 & 4.152 & 4.063 & 0.307 \\
\hline & & Total length & -0.246 & 0.192 & 0.200 & -0.228 & 0.164 & 0.164 \\
\hline
\end{tabular}


Table A6. Model output of catch vulnerability from 10 years of monitoring a community employing partially protected areas (PPA) in Solomon Islands. Cl indicates $95 \%$ confidence intervals from Generalized Additive Models (GAMs).

\begin{tabular}{lccc}
\hline \hline & \multicolumn{3}{c}{ Vulnerability } \\
Predictors & Estimates & $\mathrm{Cl}$ & $p$ \\
\hline (Intercept) & 44.25 & $43.62-44.88$ & $<\mathbf{0 . 0 0 1}$ \\
& & & \\
Management - PPA & -1.58 & $-2.58--0.57$ & $\mathbf{0 . 0 0 2}$ \\
Smooth term & 0.97 & & $<\mathbf{0 . 0 0 1}$ \\
(Year) : & & & \\
Management - Open & & \\
$\begin{array}{l}\text { Smooth term } \\
\text { (Year) : }\end{array}$ & 1.90 & $\mathbf{0 . 0 0 1}$ \\
Management - PPA & & \\
\hline Observations & 933 & \\
Marginal R & 0.135 & \\
\end{tabular}



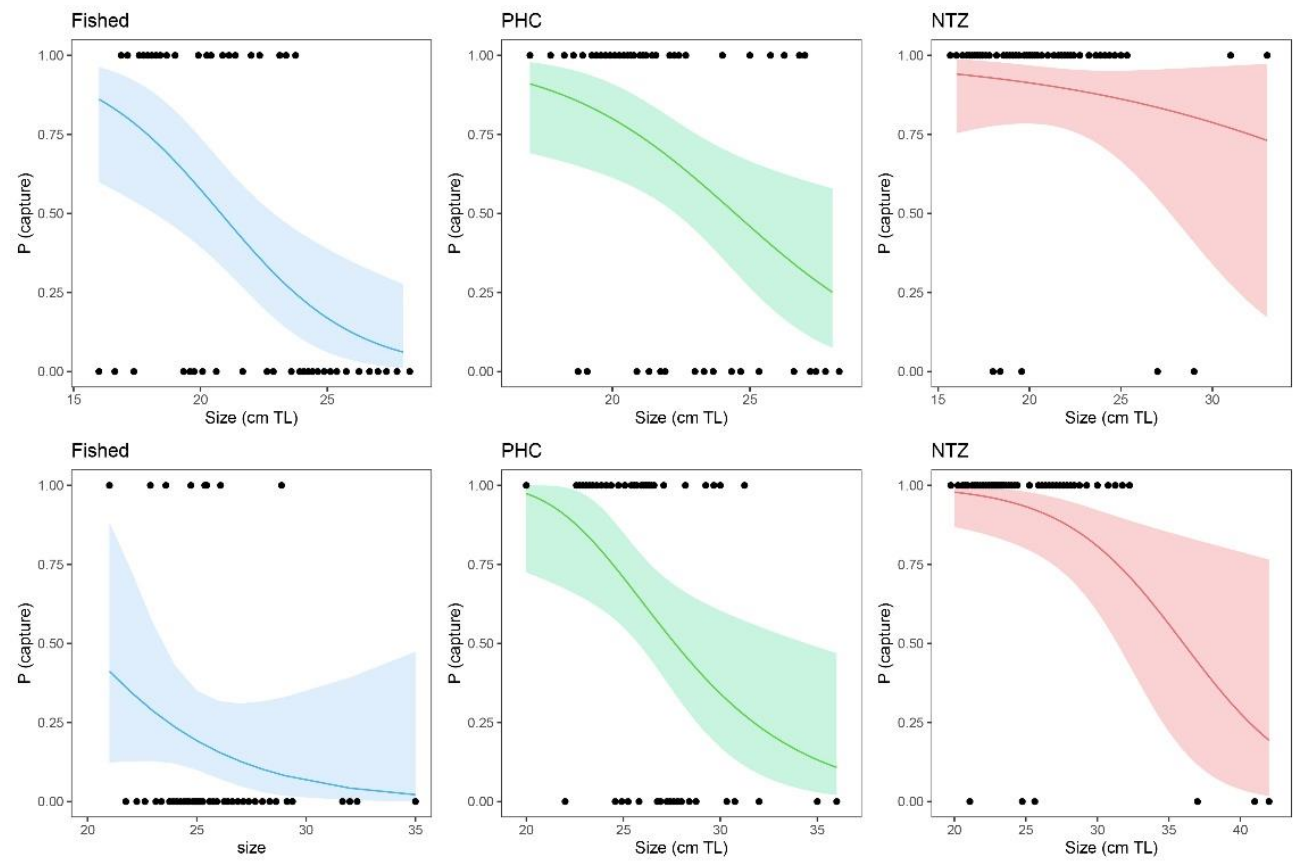

Figure A1. Differences in probability of approaching within spearing range with fish size (total length) for the family Acanthuridae and labrid subfamily Scarinae between co-management strategies. Probability of capture is defined as the likelihood of approaching to within upper spearing distance $(3.6 \mathrm{~m})$ of a reef fish. 



Figure A2. Differences in probability of approaching within spearing range with fish size (total length) for the family Acanthuridae and labrid subfamily Scarinae between co-management strategies. Probability of capture is defined as the likelihood of approaching to within upper spearing distance $(3.05 \mathrm{~m})$ of a reef fish. 

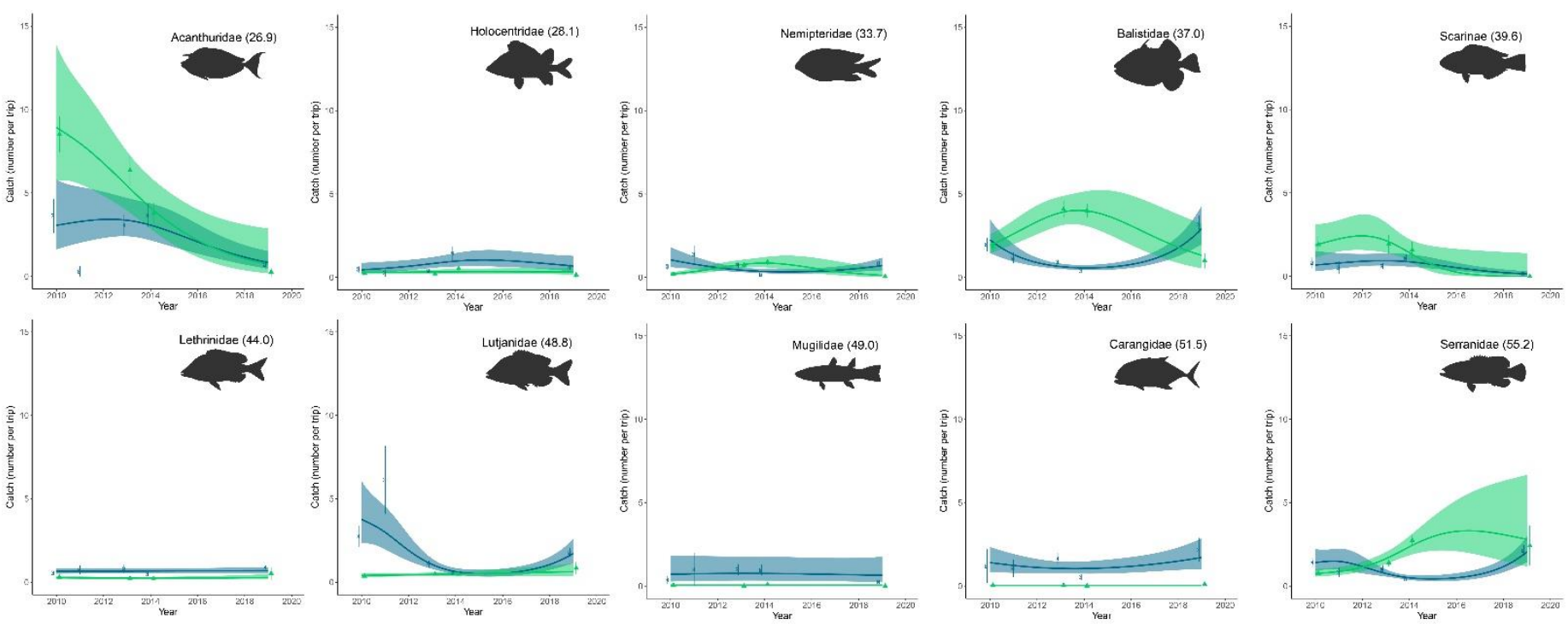

Figure A3. Temporal patterns in reef fish catch between open (Blue) and partially protected (PPA) (Green) reefs in Solomon Islands for the ten most commonly caught families. Each family comprised at least five percent of estimated total annual catch. Points represent mean \pm SE values for each year on open and PPA reefs. Splines represent GAM model predictions $\pm 95 \%$ confidence intervals. Families are arranged according to increasing vulnerability with mean vulnerability values across species captured within each family in parenthesis. 